\title{
A PRIMER ON
}

\section{PALEOLIQUEFACTION INVERSE}

ANALYSIS AND ITS RESEARCH

POTENTIAL IN CASCADIA

\begin{tabular}{l|l} 
Brett Maurer & $\begin{array}{l}\text { Department of Civil \& Environmental Engineering } \\
\text { University of Washington }\end{array}$
\end{tabular} 


\section{OUTLINE}

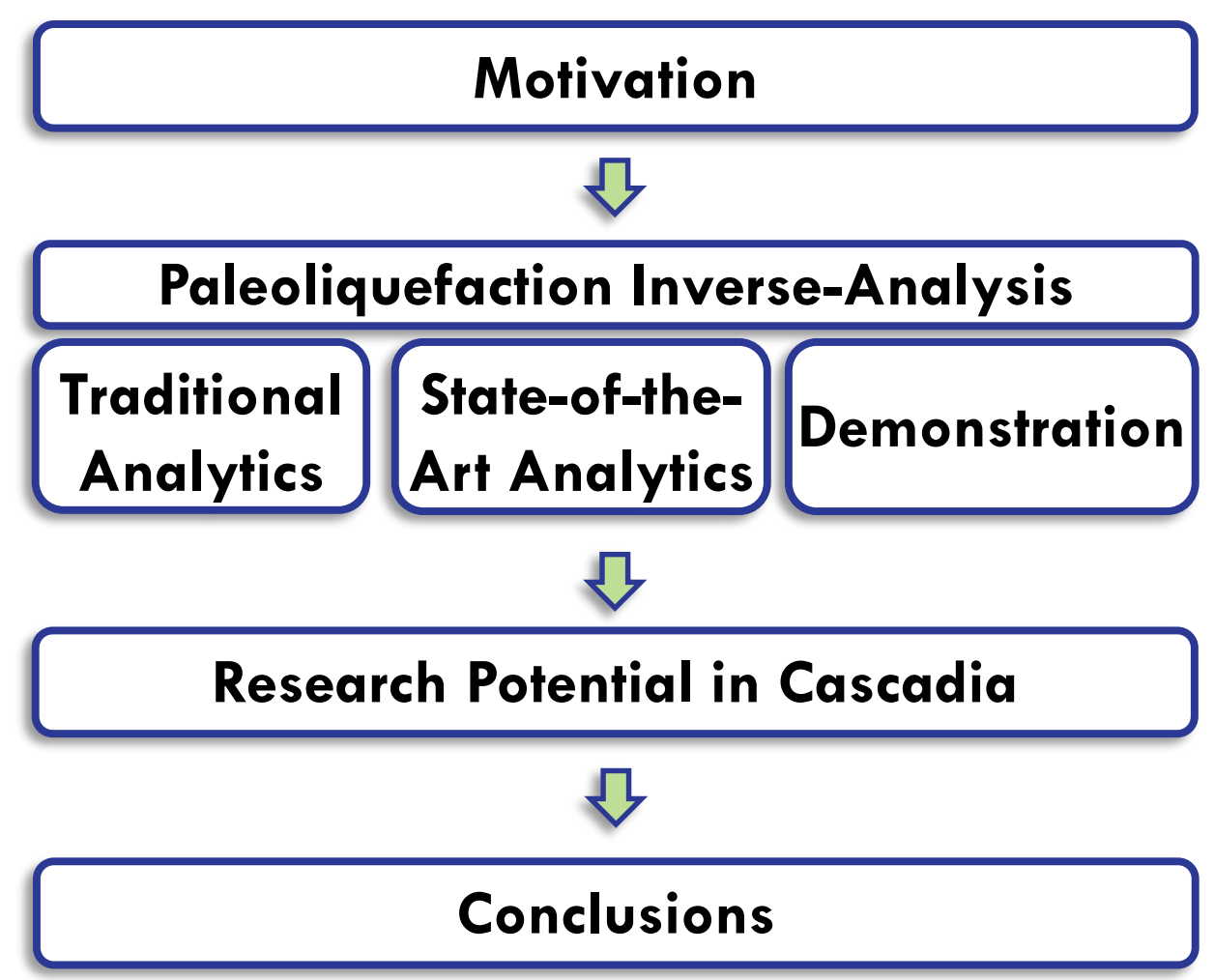




\section{OUTLINE}

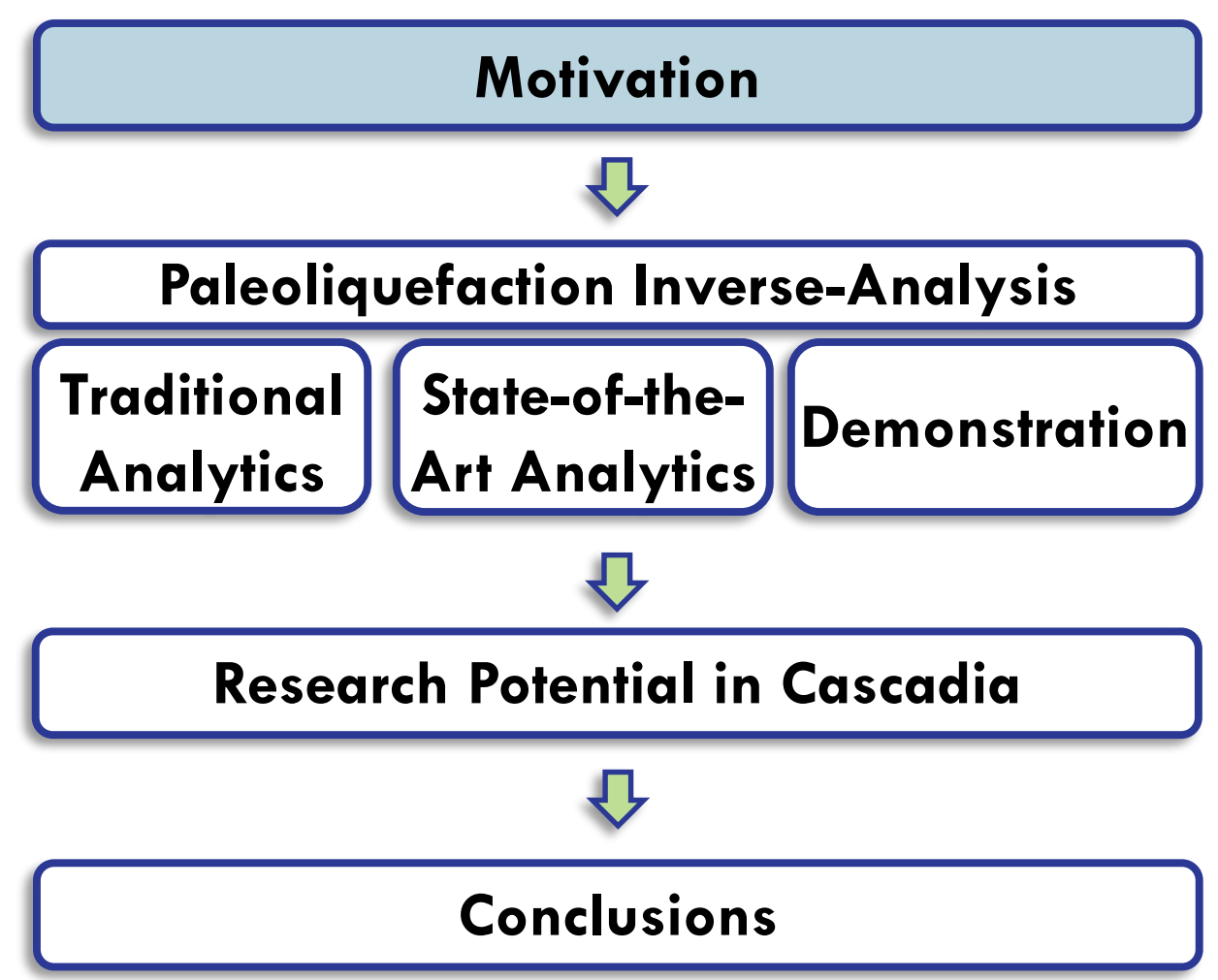




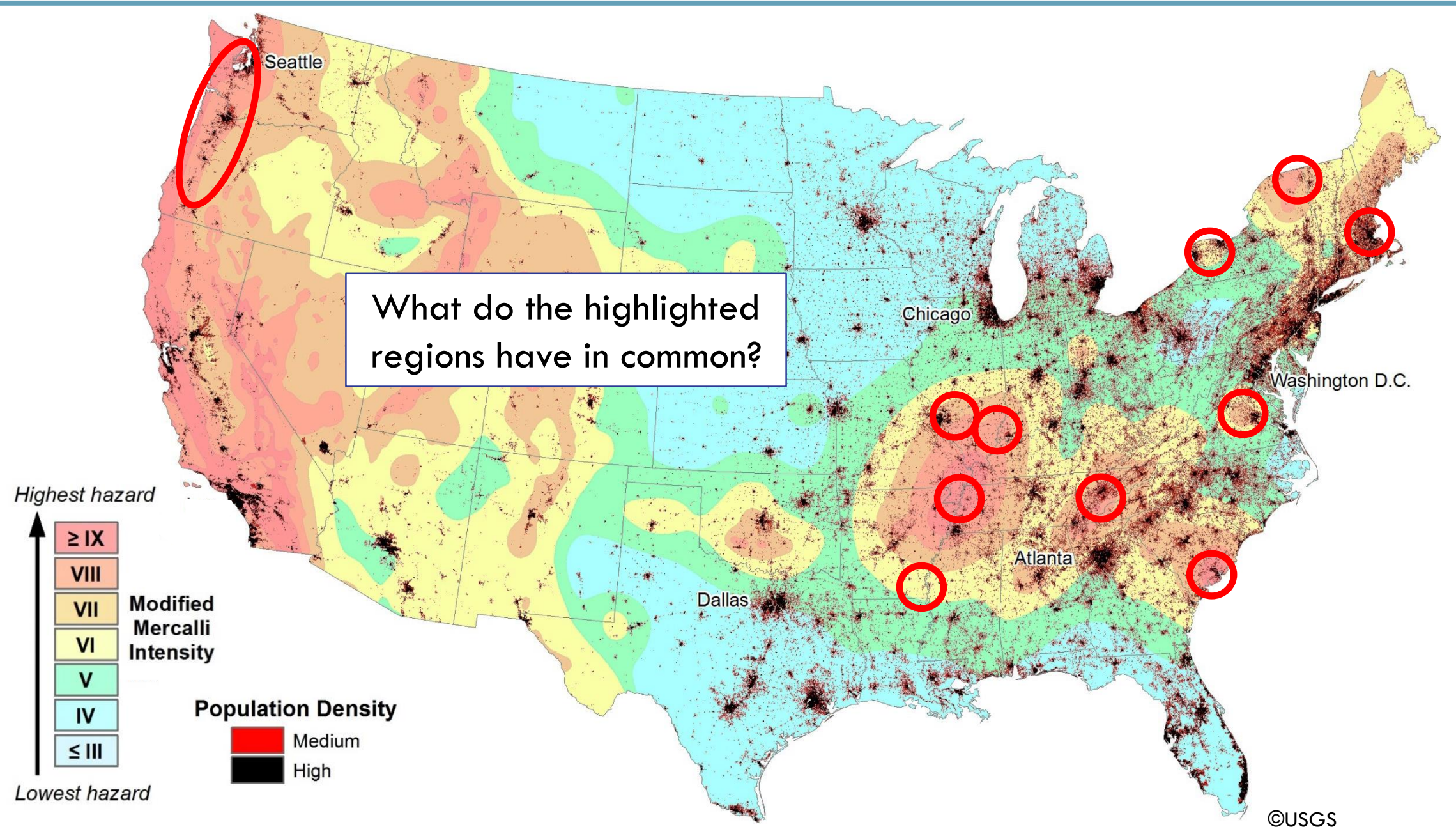




\section{OUTLINE}

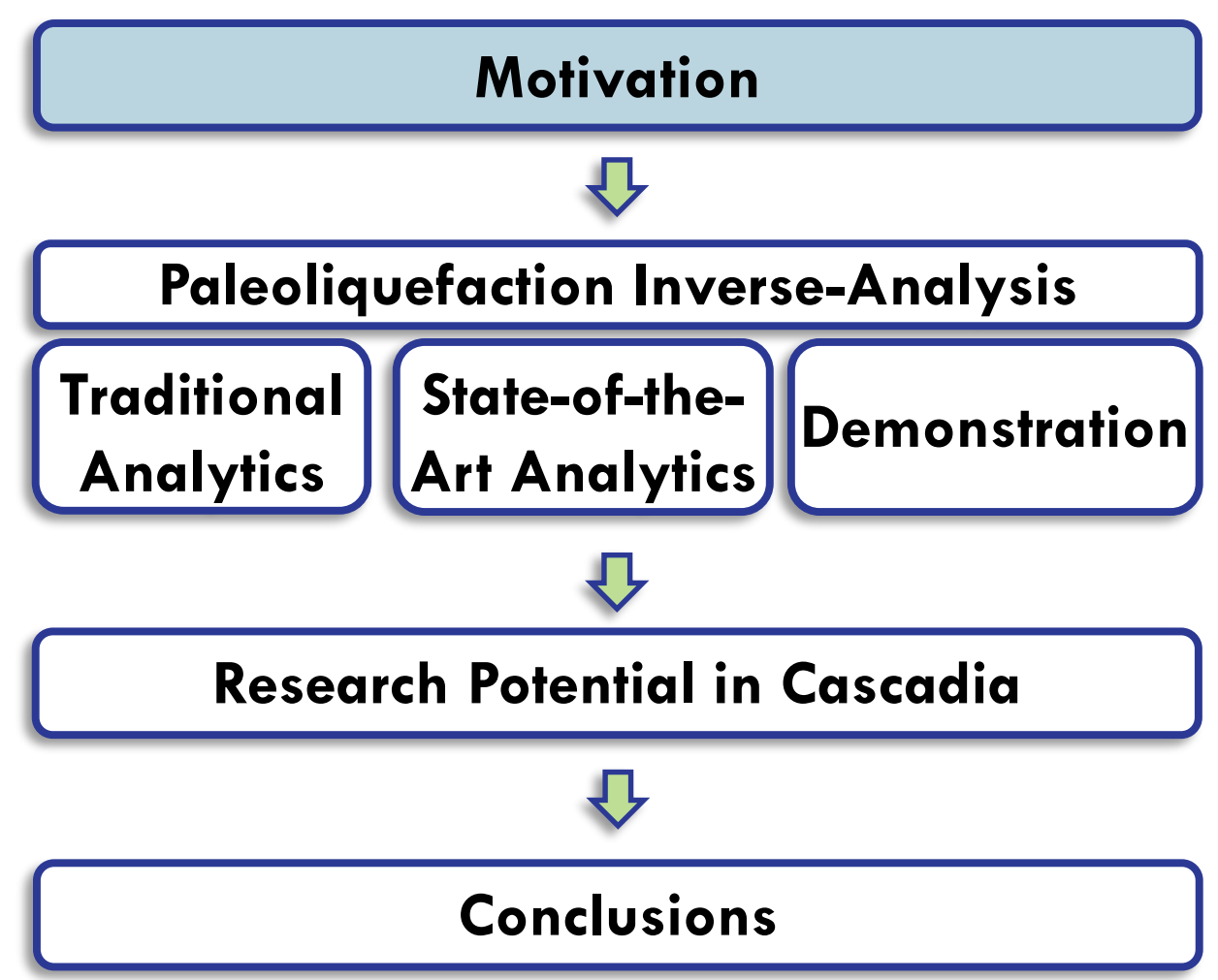




\section{OUTLINE}

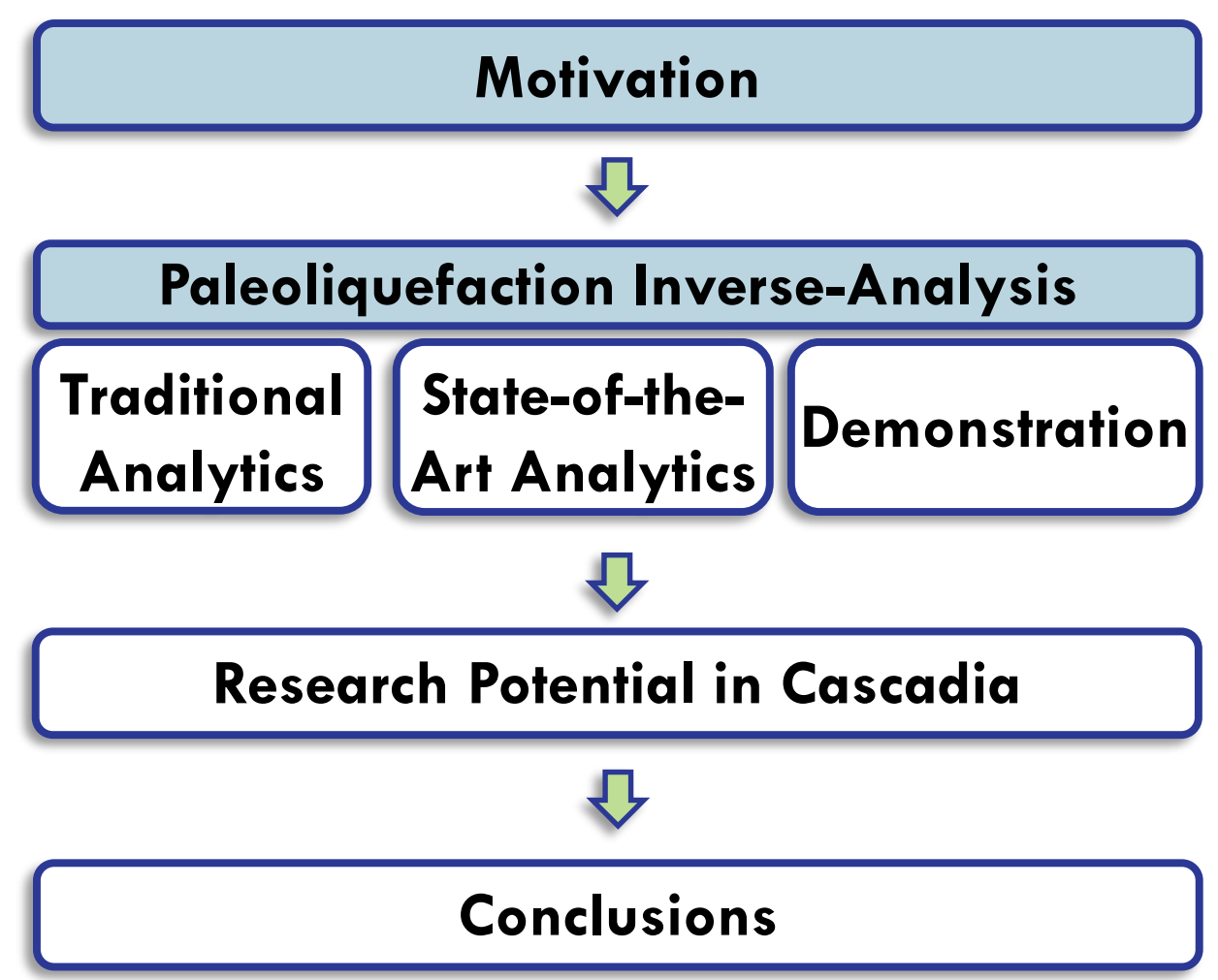


Phases of Paleoliquefaction Analysis

Phase 1: Field Interpretation

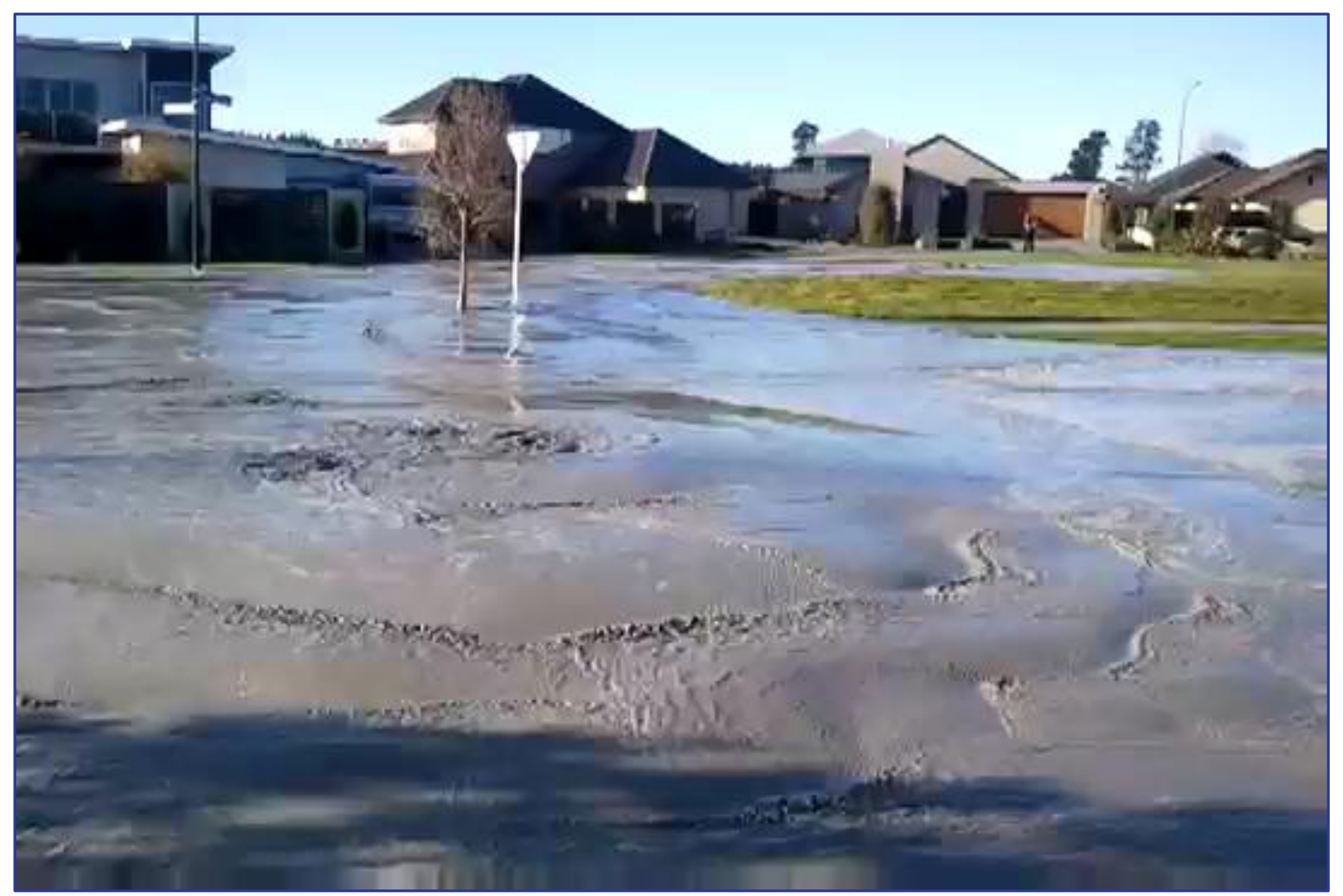

Liquefaction during 2010-2011 Canterbury Earthquakes 


\section{Phase 1: Field Interpretation}

- Locate features

- Seismically induced?

- Date (e.g., C-14; OSL; stratigraphy) and tentatively group features
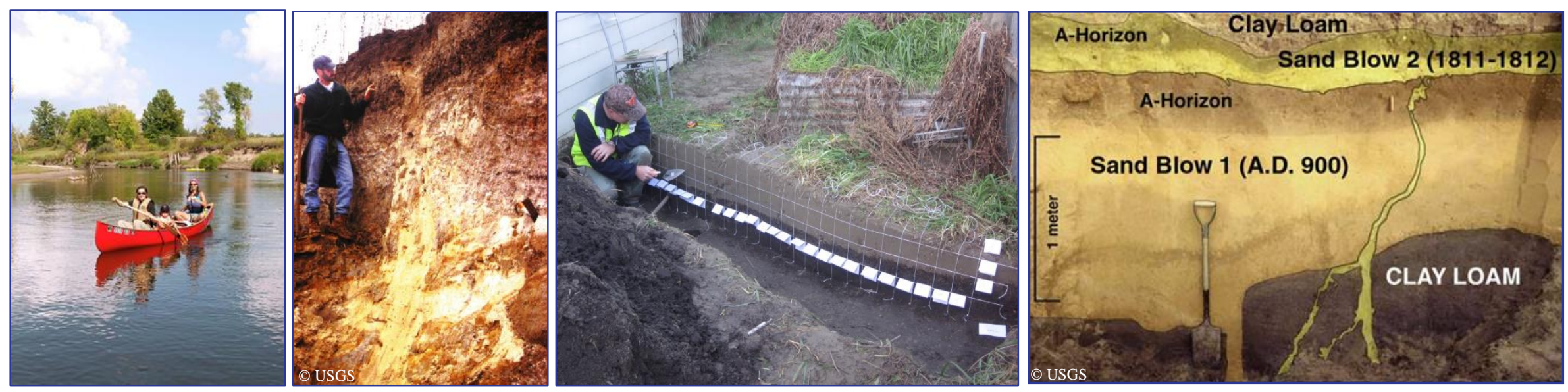
Phases of Paleoliquefaction Analysis

\section{Phase 1: Field Interpretation}
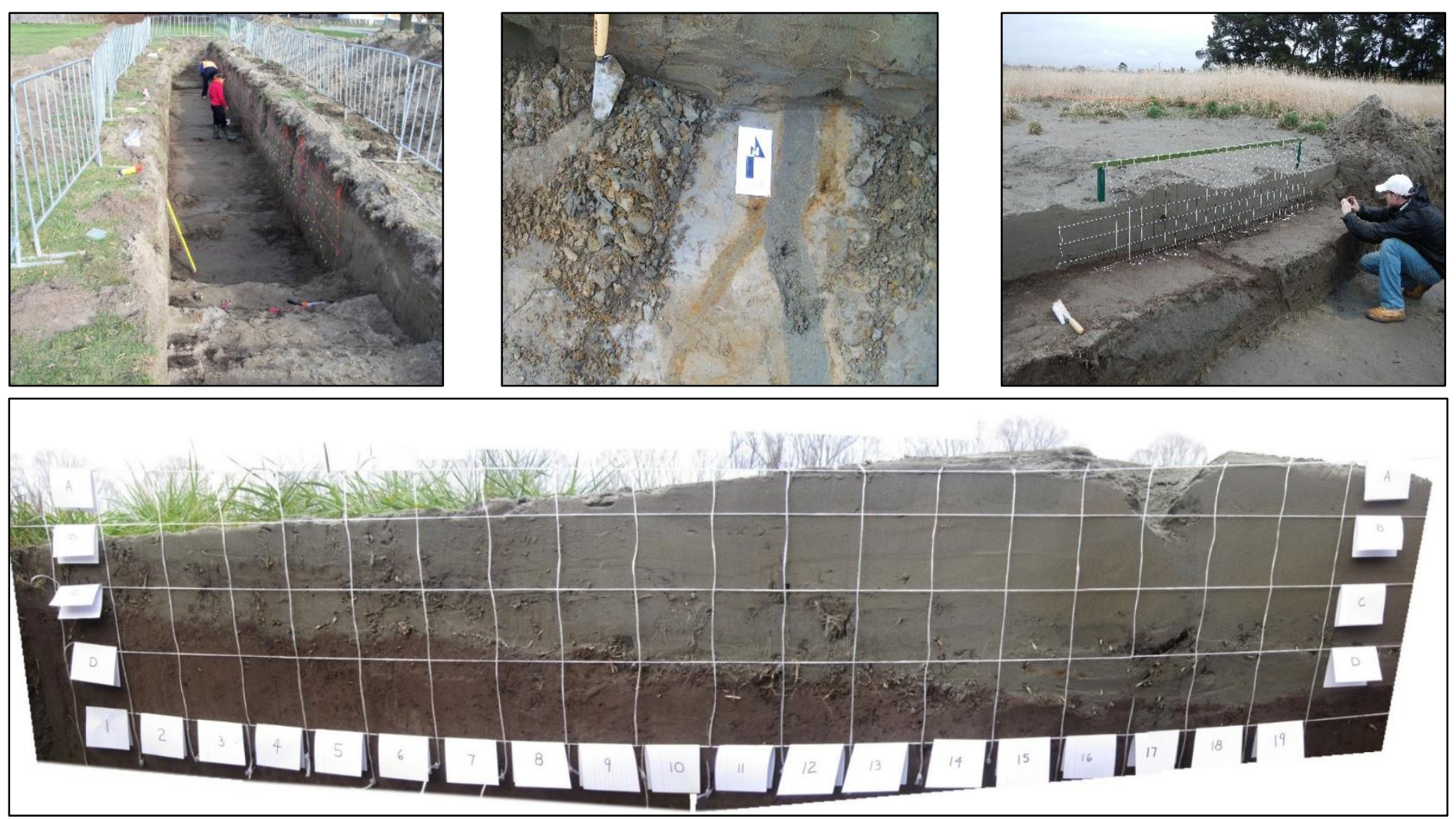

Trenching modern and paleo-liquefaction features in NZ 
Phases of Paleoliquefaction Analysis

Phase 2: Inverse-analysis to compute seismic parameters
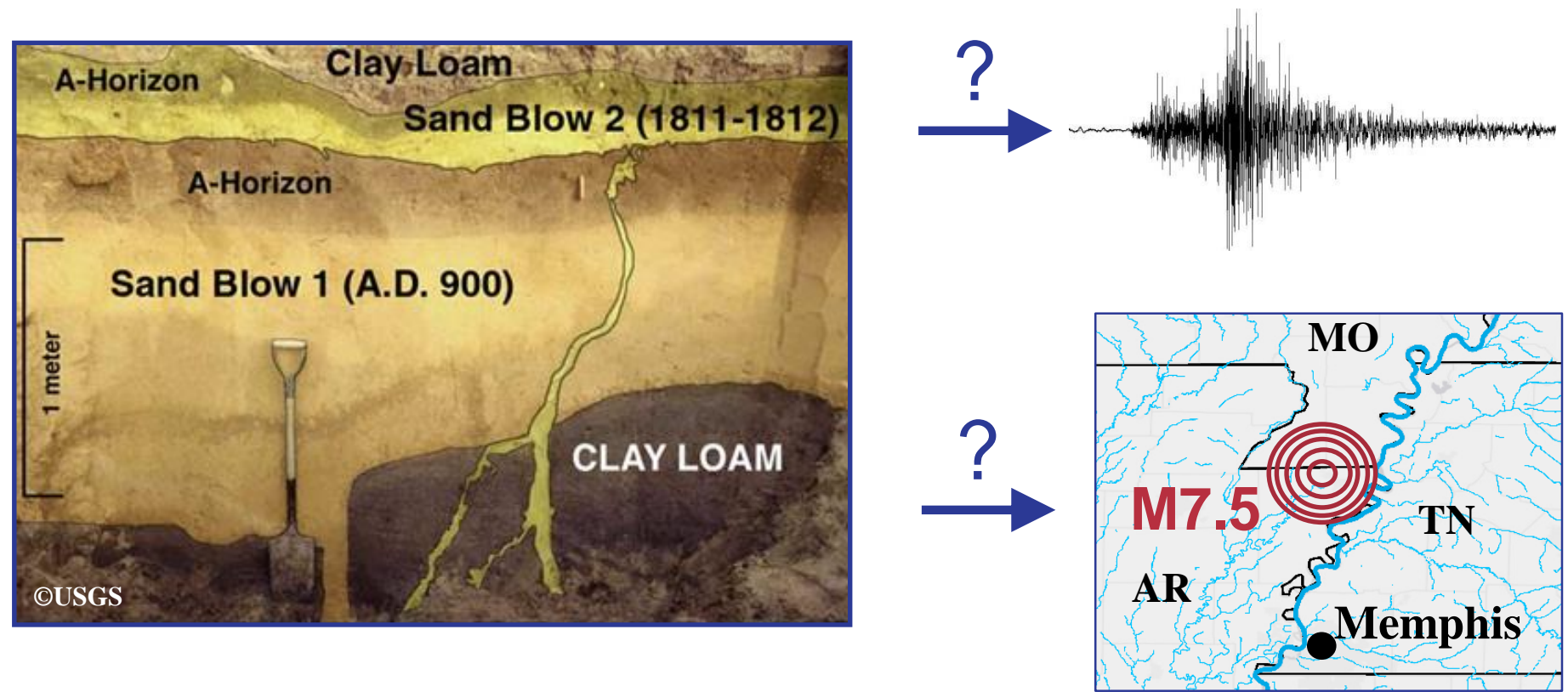


\section{OUTLINE}

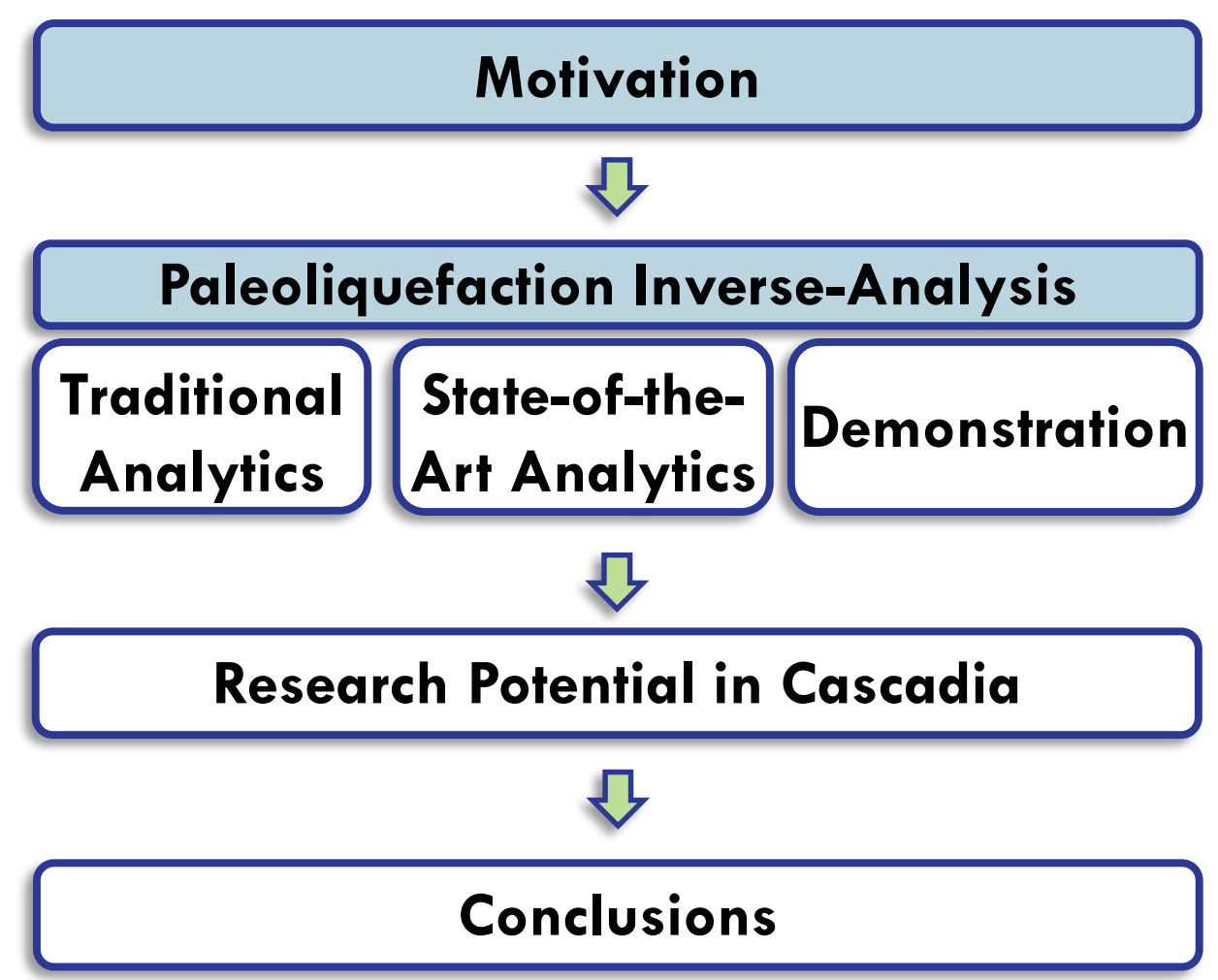




\section{OUTLINE}

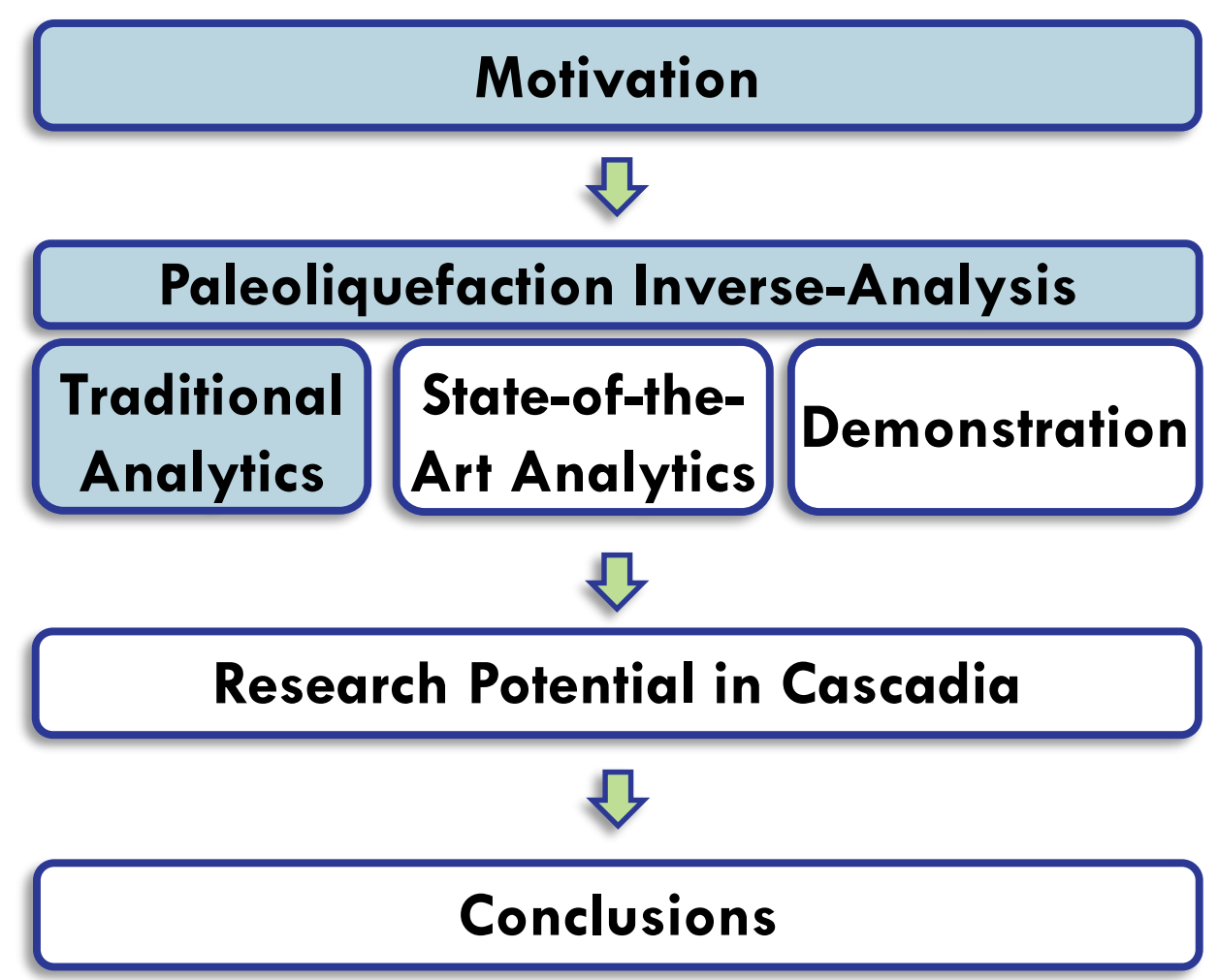


Magnitude-Bound

Correlation

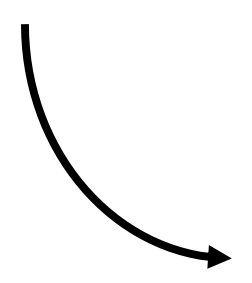

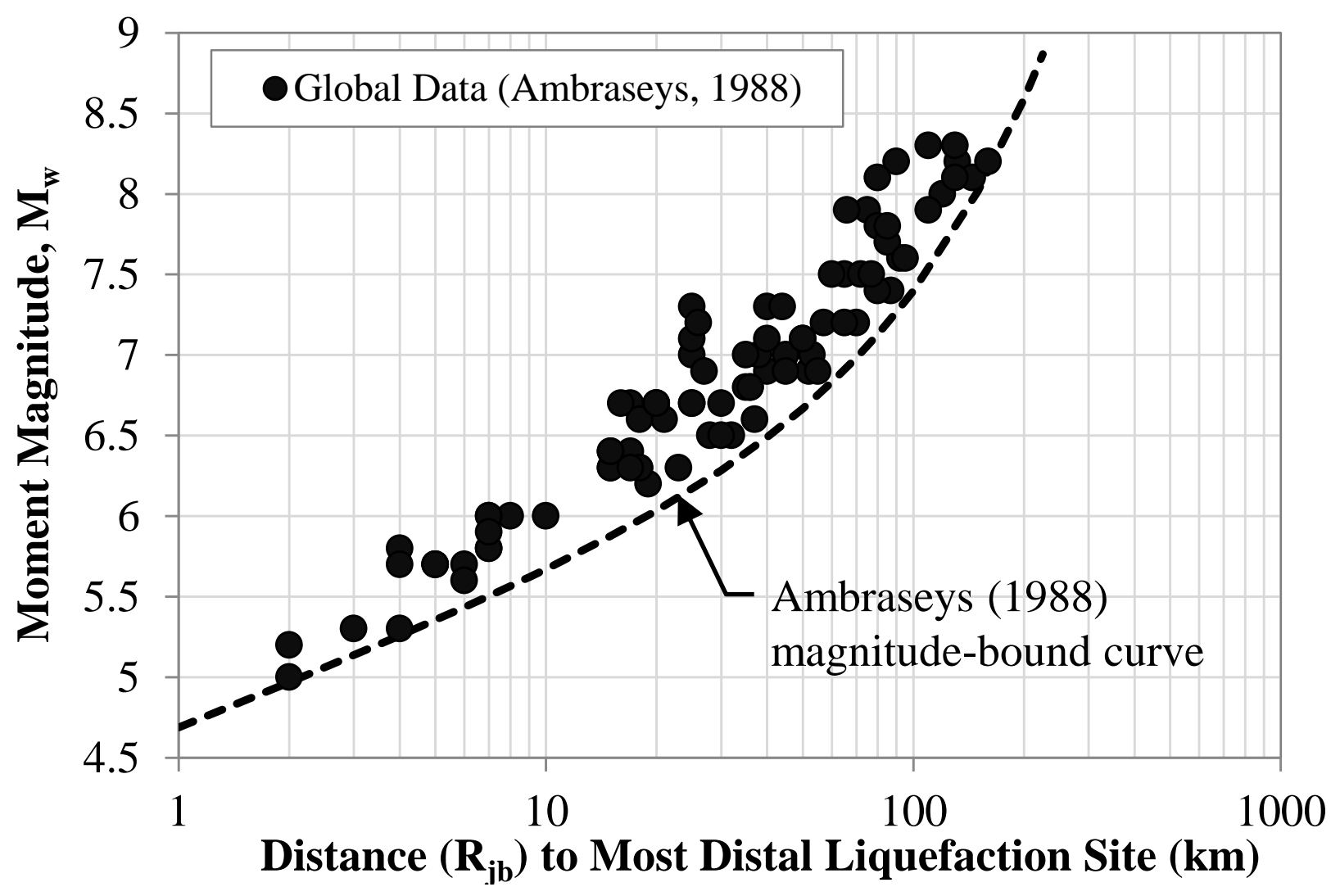


Magnitude-Bound

Correlation

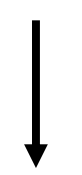

Application

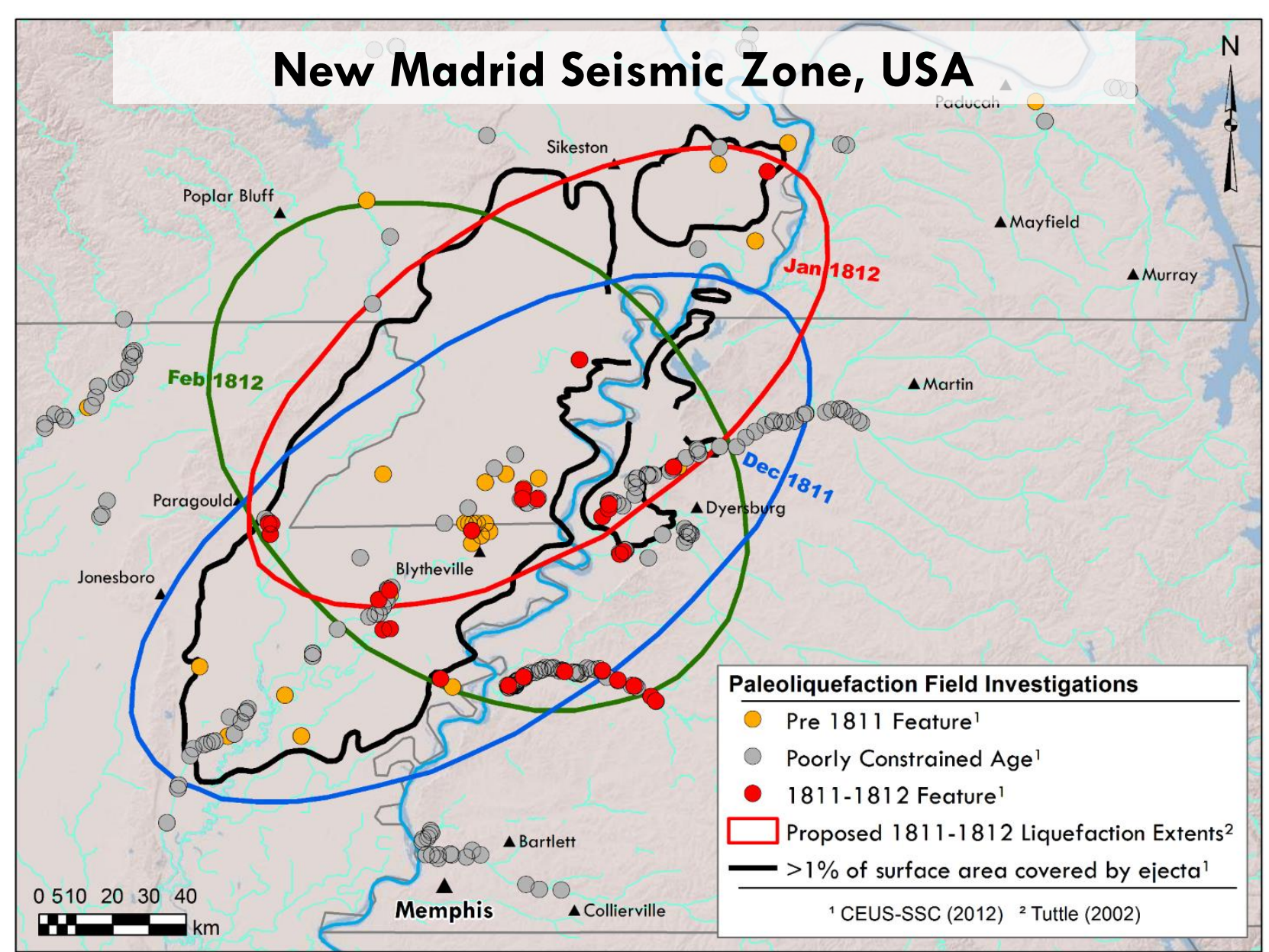




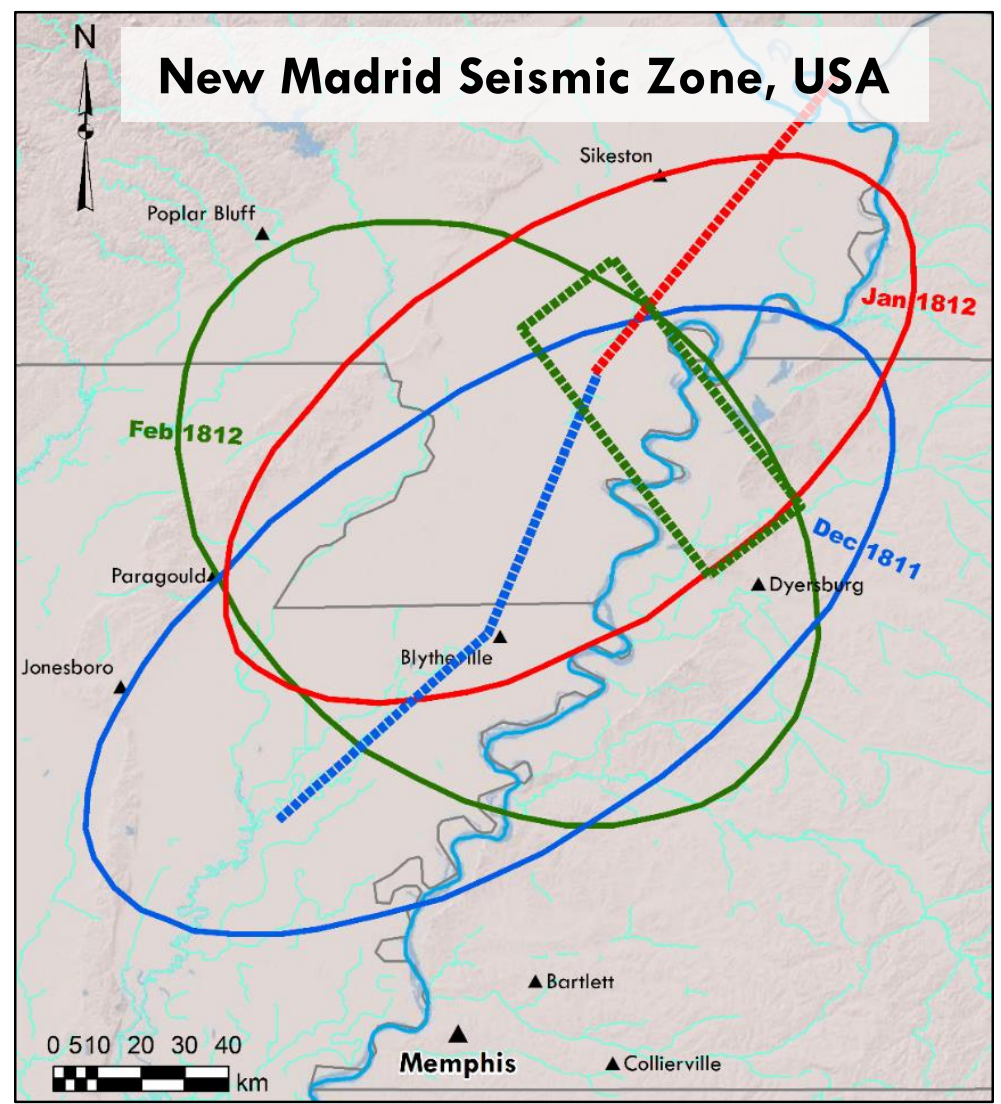

CEUS-SSC (2012) Preferred Rupture Scenario

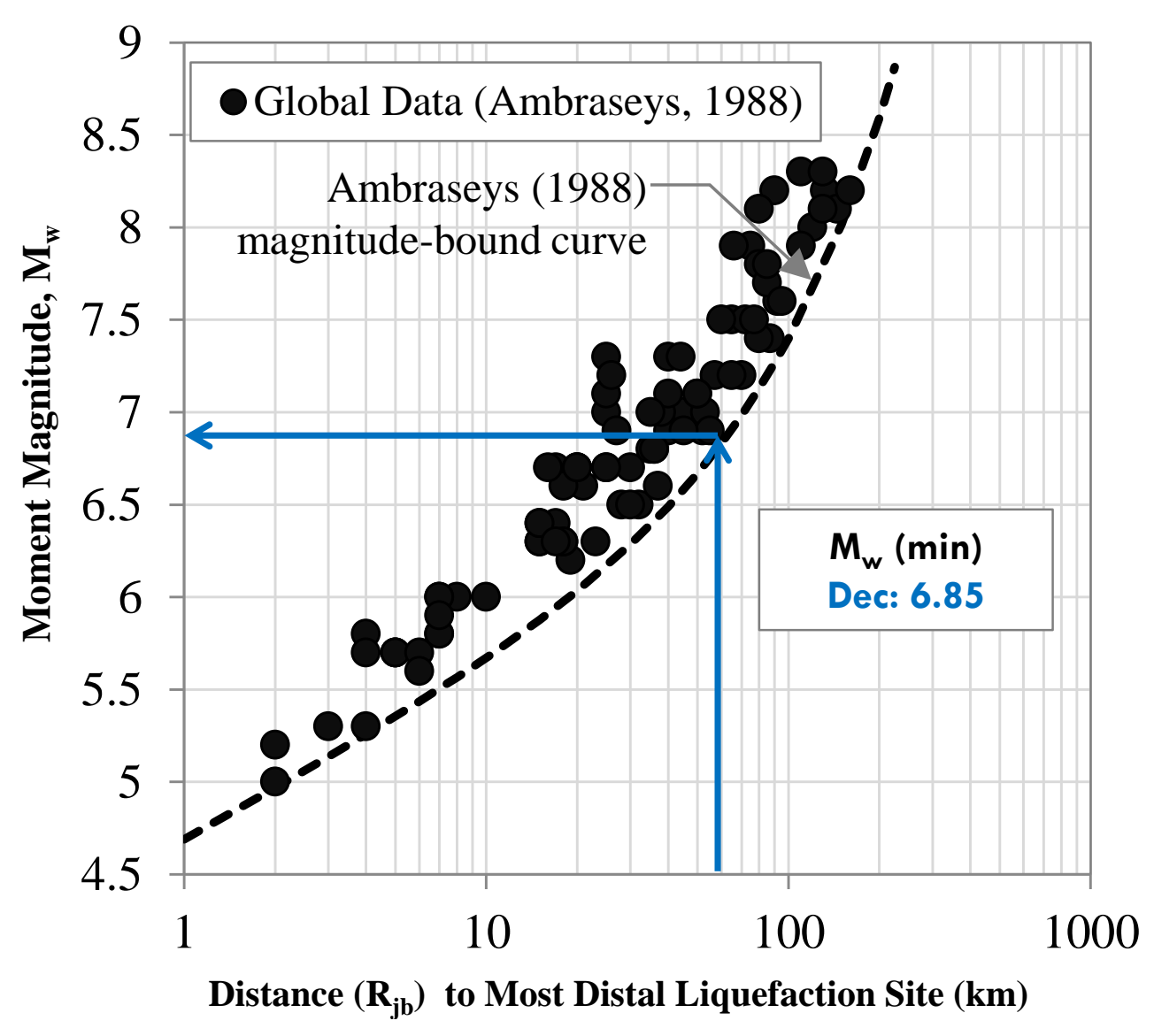




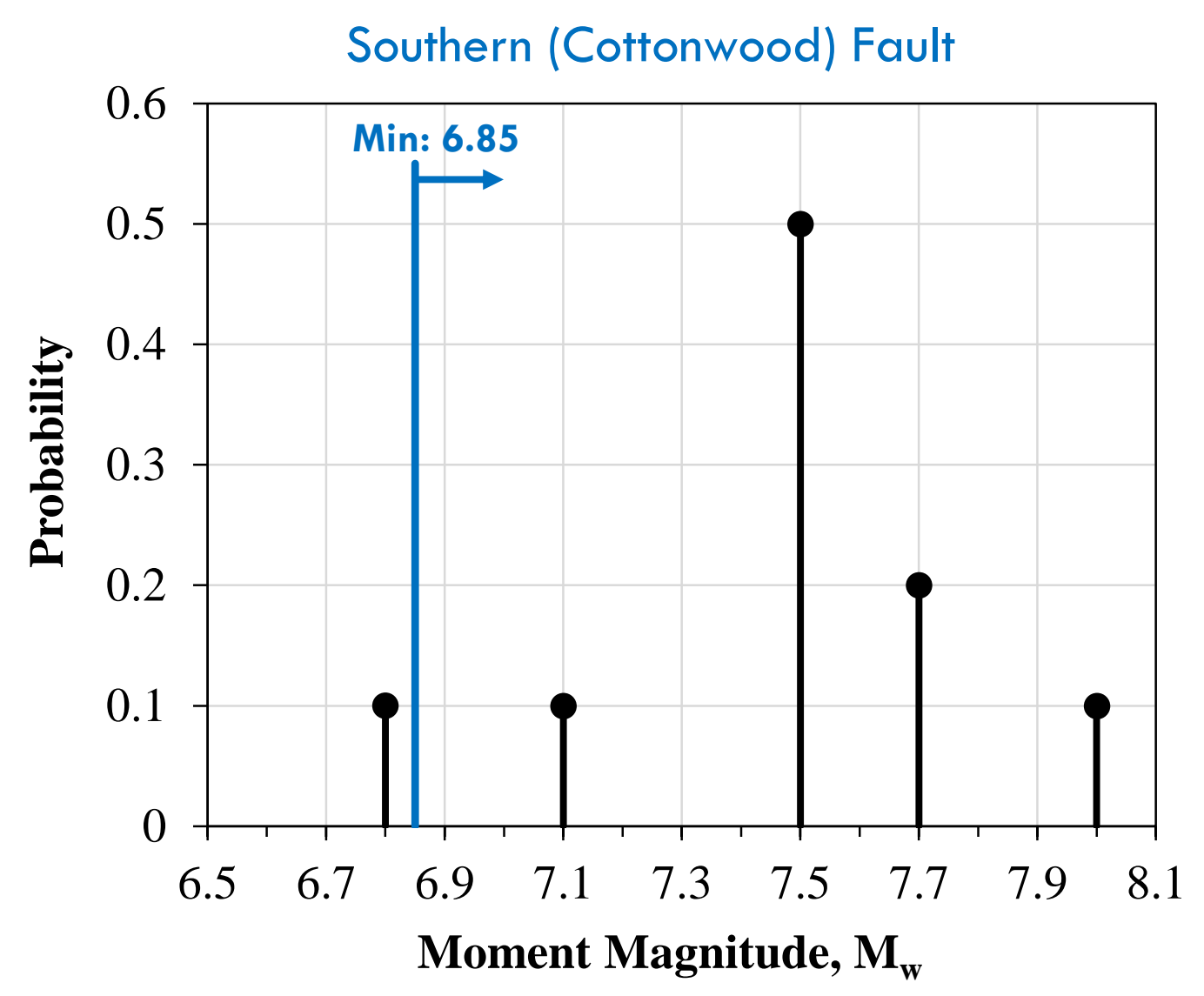

2014 USGS NSHMP Rupture Magnitude Probabilities 
Limitation \#1: Provides only a lower-bound estimate of magnitude

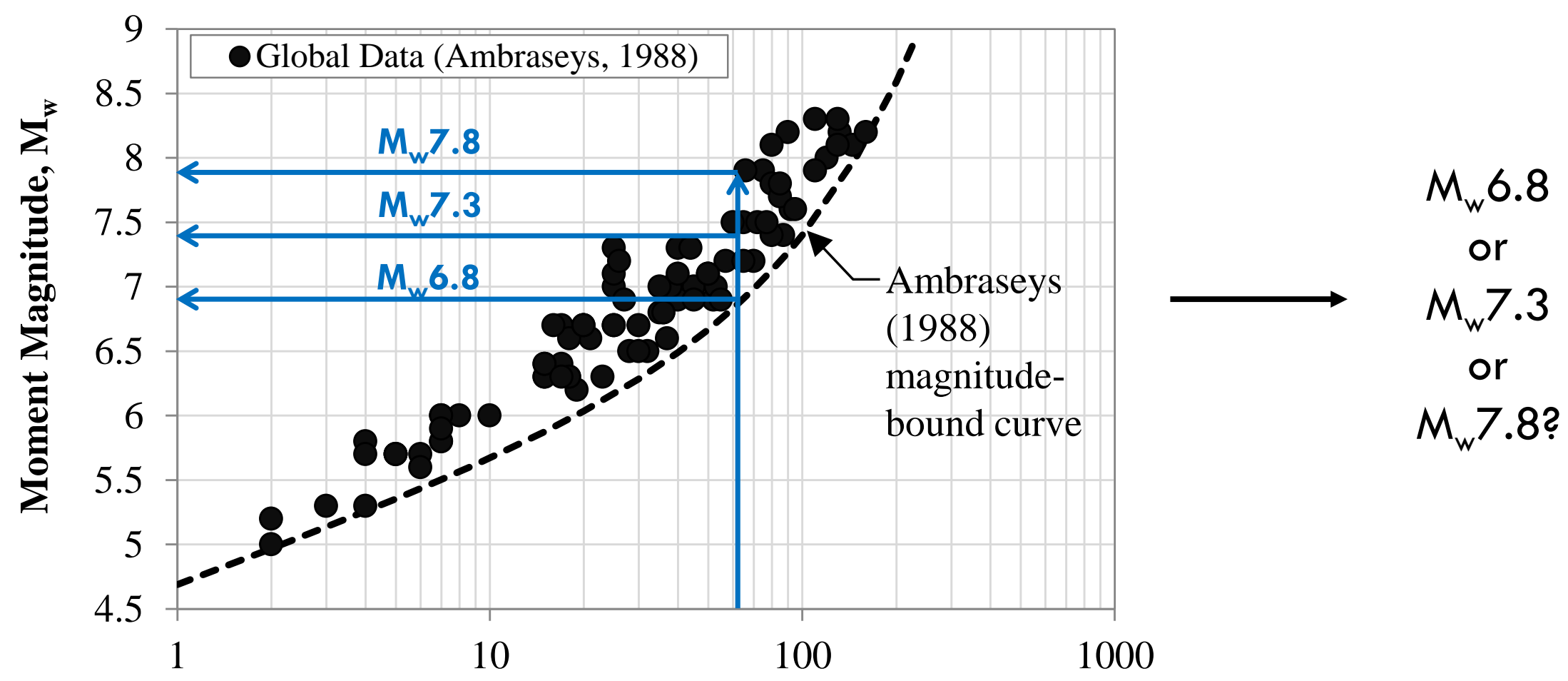

Distance $\left(\mathbf{R}_{\mathbf{j b}}\right)$ to Most Distal Liquefaction Site (km) 
Limitation \#2: Provides no quantification of uncertainty

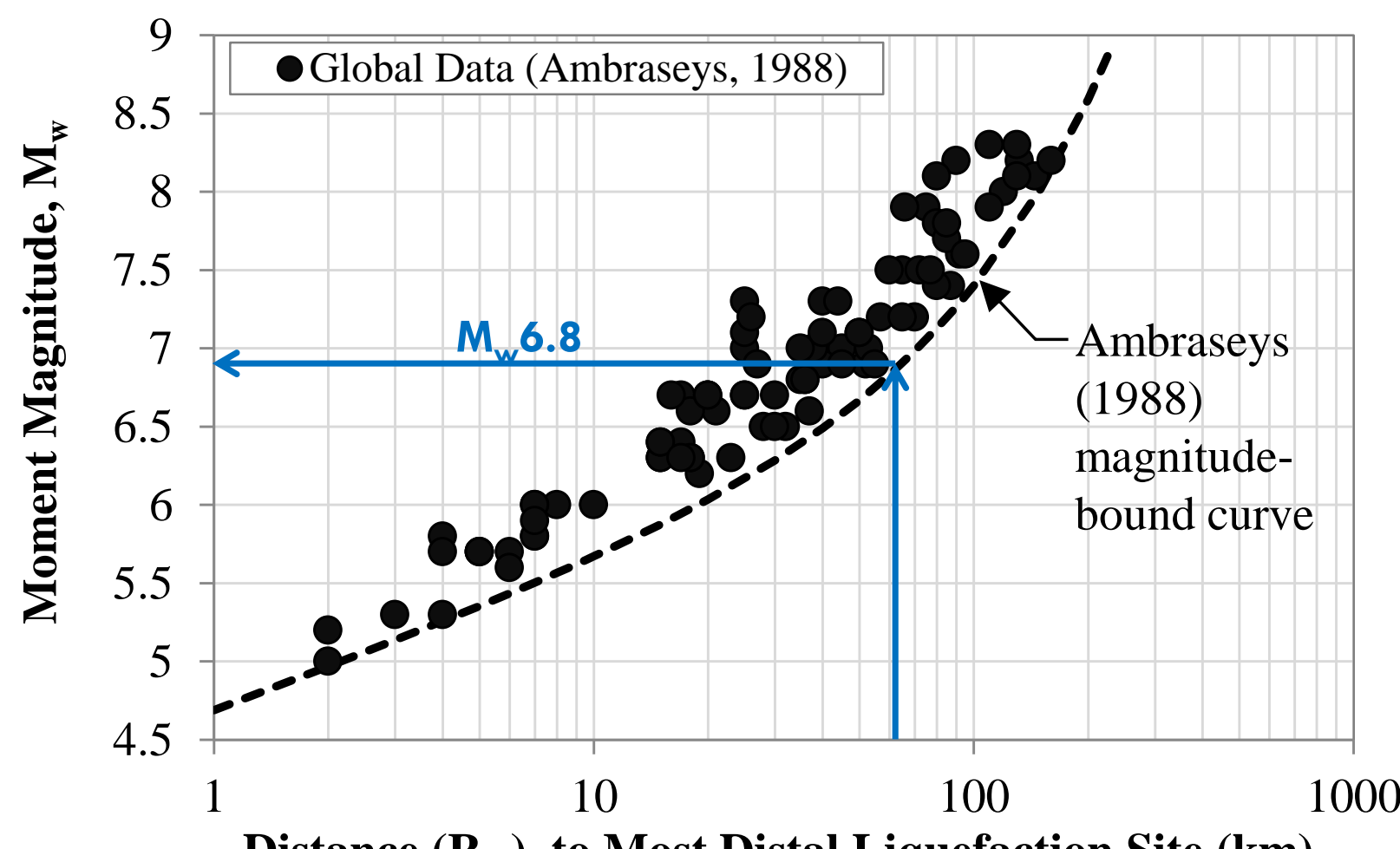

What does "lower-bound" really mean?

Distance $\left(\mathbf{R}_{\mathbf{j b}}\right)$ to Most Distal Liquefaction Site $(\mathbf{k m})$ 


\section{Limitation \#3: Commonly relies on global correlations}

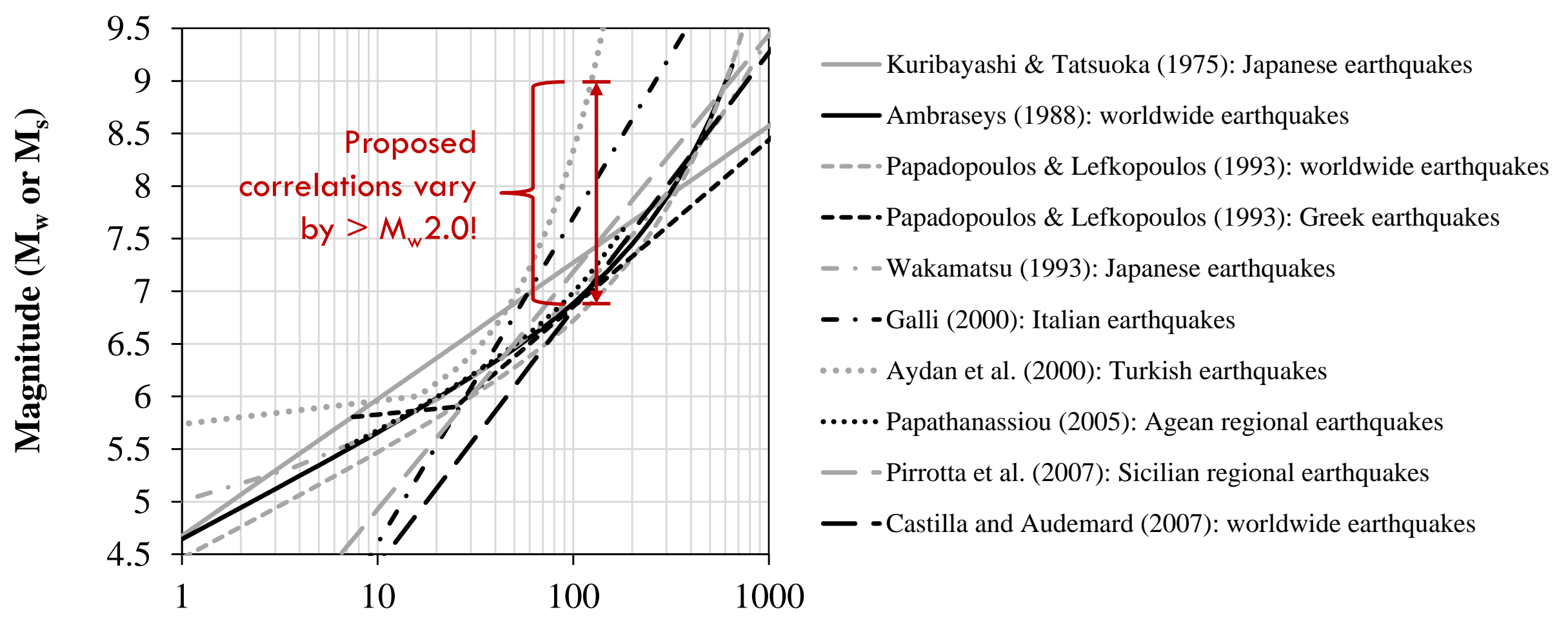

Distance to Most Distal Liqeufaction Site (km) 
Limitation \#4: Relies on field observations... what if earthquakes are too infrequent?

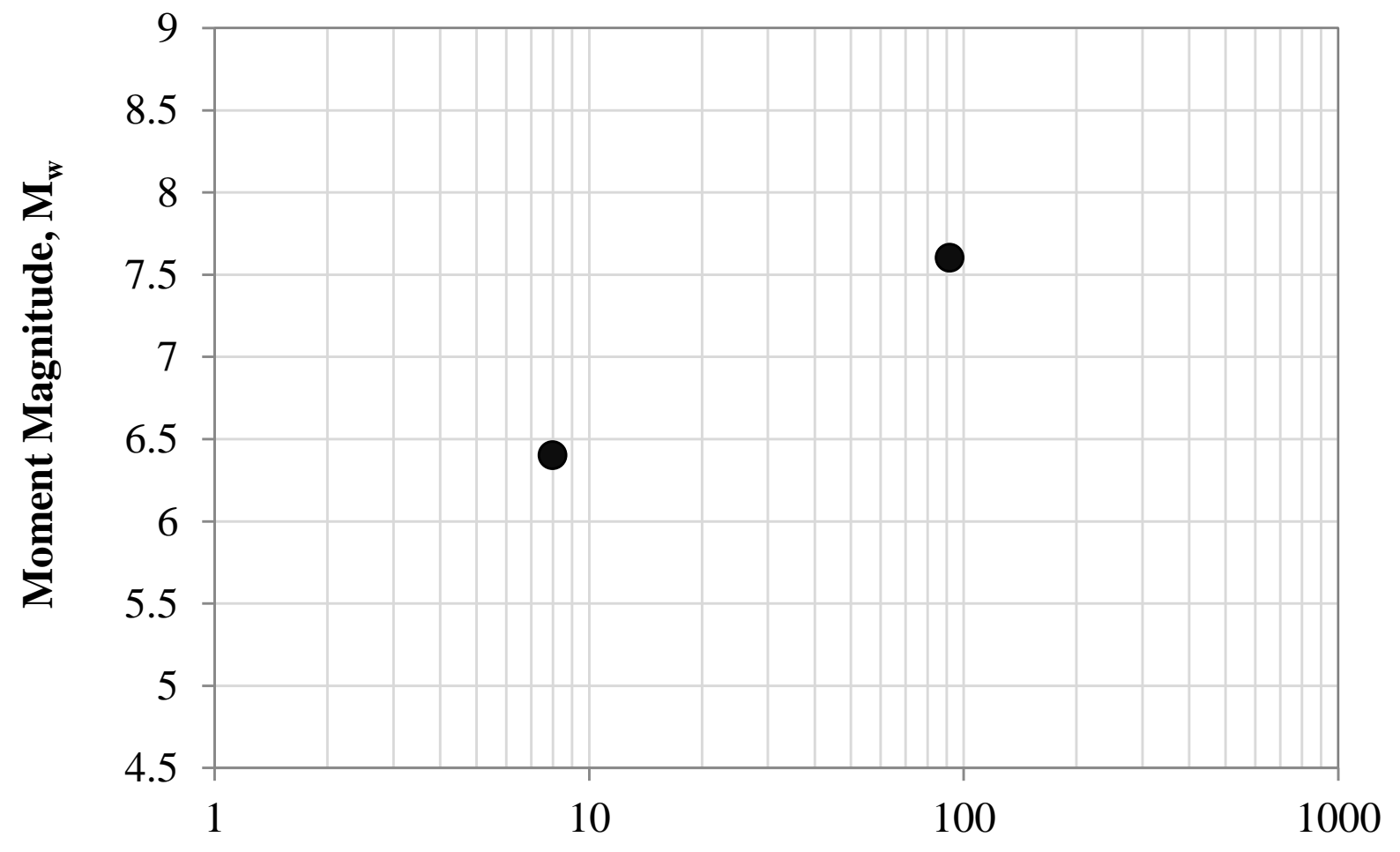

How do we develop a correlation from this data?

Distance $\left(\mathbf{R}_{\mathbf{i b}}\right)$ to Most Distal Liquefaction Site $(\mathbf{k m})$ 


\section{Can magnitude-bound correlations be developed without field observations?}

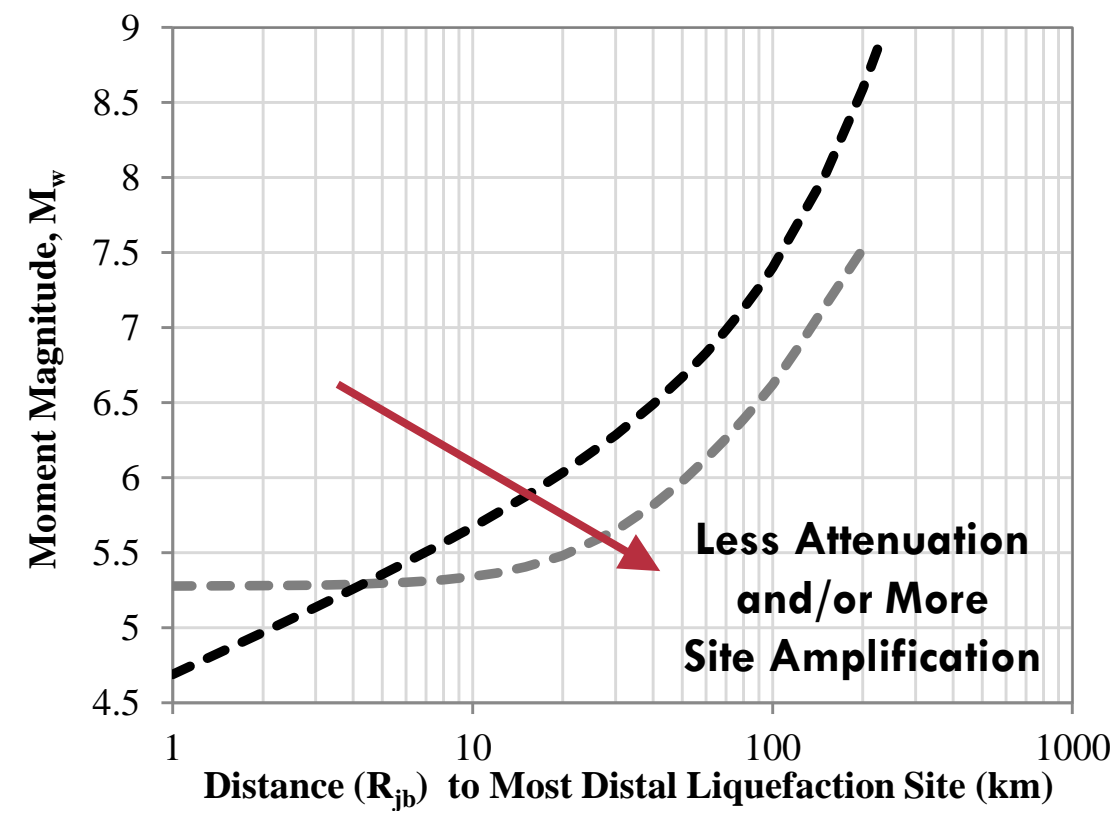

Intuitively, we may deduce that:

The curve shape is a function of energy attenuation \& site response 


\section{Can magnitude-bound correlations be developed without field observations?}

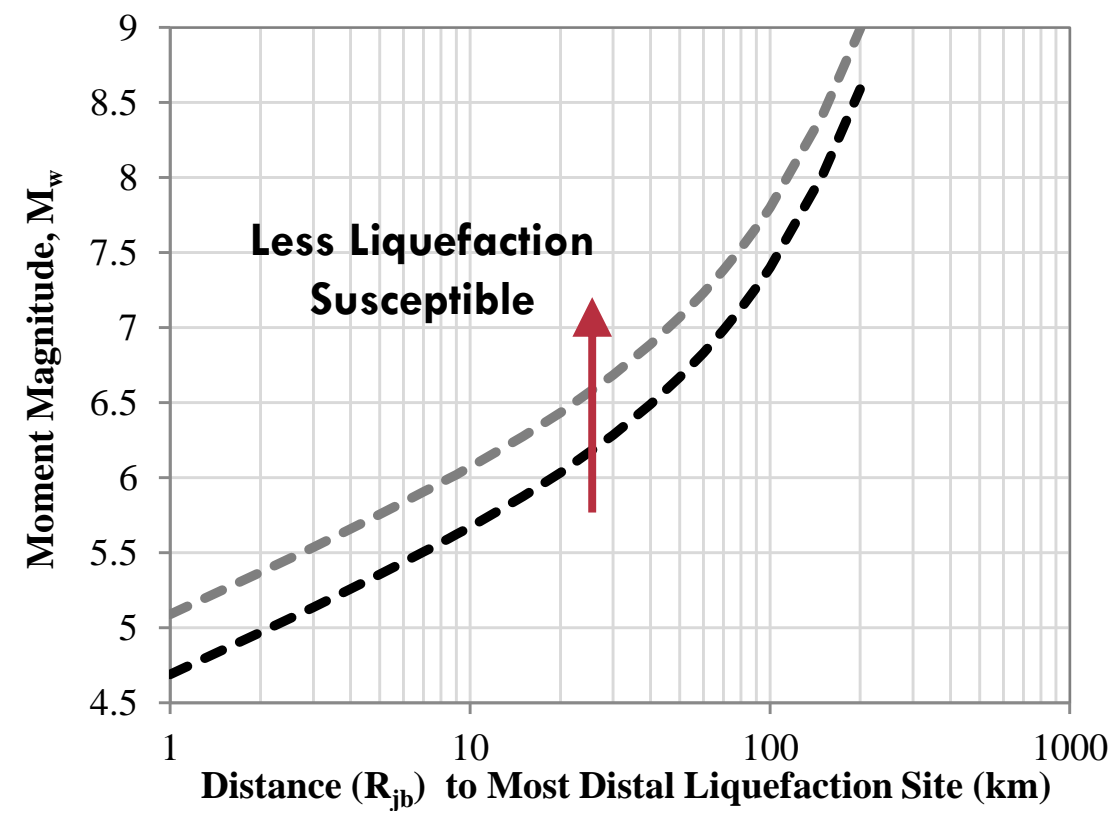

Intuitively, we may deduce that:

The curve shape is a function of energy attenuation \& site response

The curve position is a function of liquefaction susceptibility 


\section{Can magnitude-bound correlations be developed without field observations?}

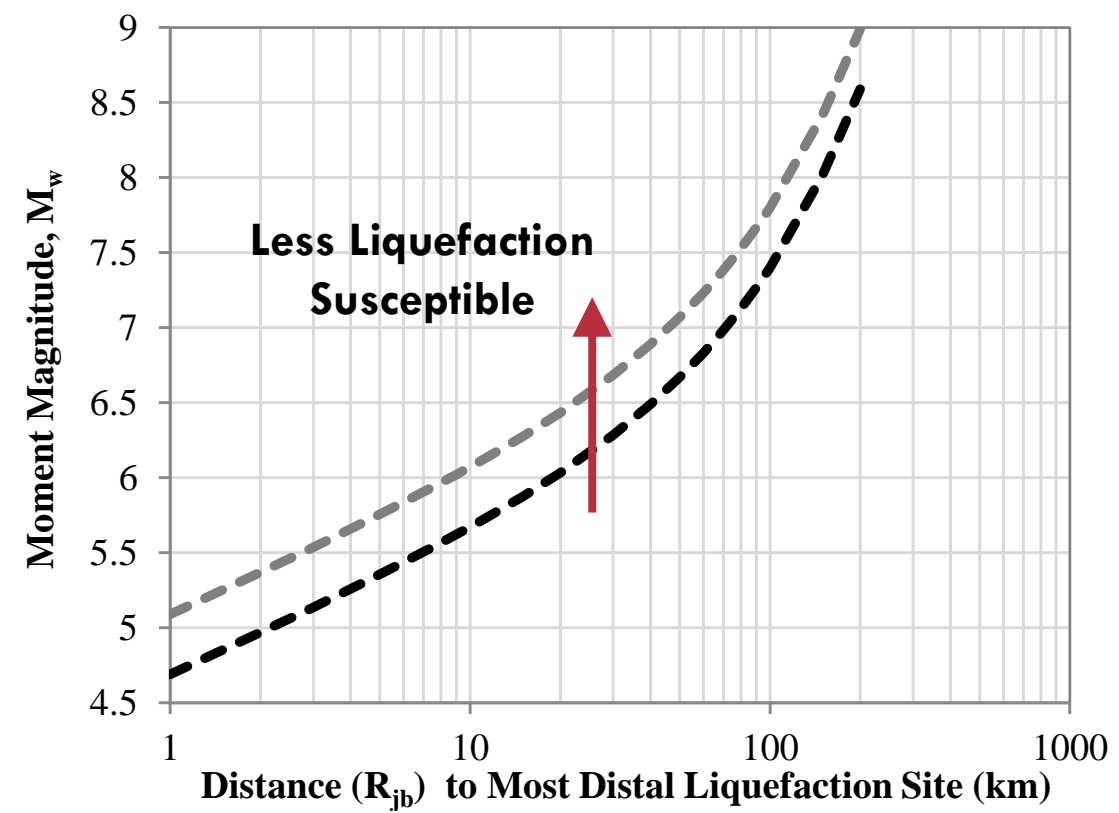

Intuitively, we may deduce that:

The curve shape is a function of energy attenuation \& site response

The curve position is a function of liquefaction susceptibility

We know what factors control the curve. Can we compute curves without field observations? 


\section{OUTLINE}

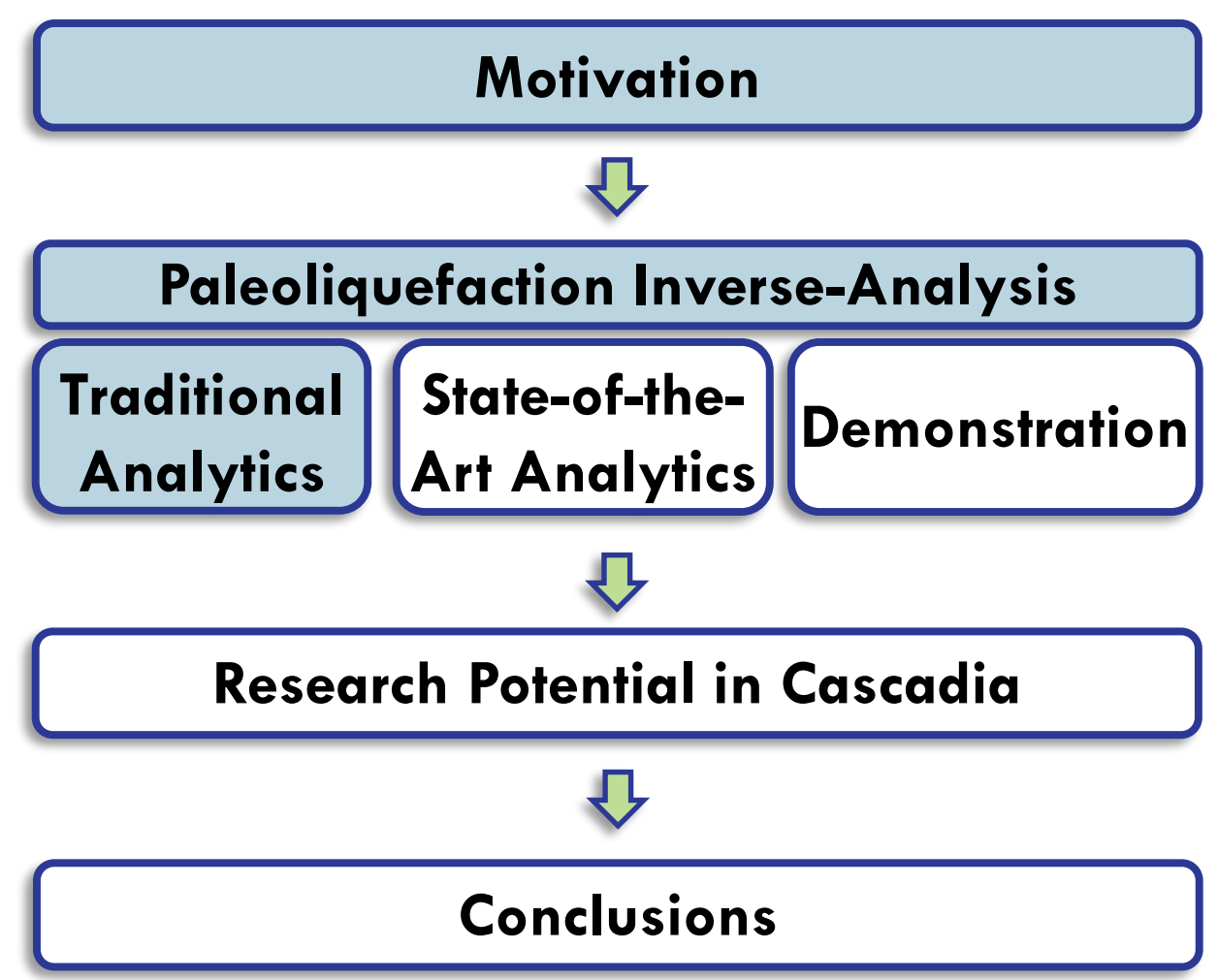




\section{OUTLINE}

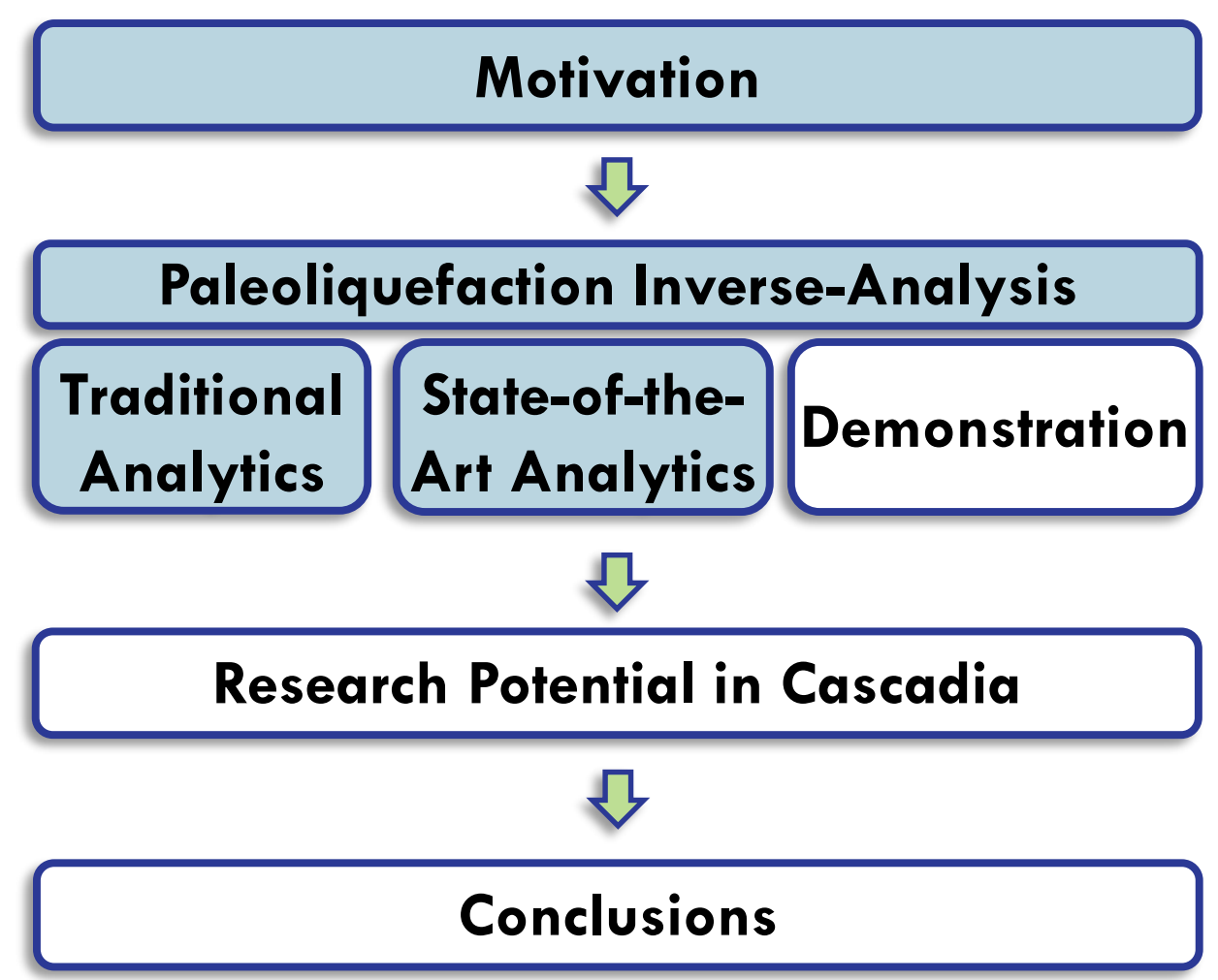




\section{Can magnitude-bound correlations be developed without field observations?}

Using (1) liquefaction triggering mechanics; (2) ground motion prediction equations; and (3) the total probability theorem to integrate over model and parameter uncertainties:

The probability that a site liquefies, given magnitude $(M)$ and site-to-source distance $(R)$, is:

Using Stress-based liquefaction triggering mechanics:

$\mathrm{P}\left(\tau \geq \tau_{t} \mid \mathrm{EQK}: \mathrm{M}, \mathrm{R}\right)=\int_{\mathrm{a}_{\max } \mathrm{r}_{\mathrm{d}}} \mathrm{P}\left(\tau \geq \tau_{t} \mid \mathrm{a}_{\max }, \mathrm{r}_{\mathrm{d}}\right) f\left(\mathrm{a}_{\max } \mid \mathrm{M}, \mathrm{R}\right) f_{\mathrm{r}_{\mathrm{d}}}\left(\mathrm{r}_{\mathrm{d}}\right) \cdot \mathrm{dr} \mathrm{r}_{\mathrm{d}} \cdot \mathrm{da} \mathrm{a}_{\max }$

Using Strain-based liquefaction triggering mechanics:

$$
\int_{\mathrm{a}_{\max }}^{\mathrm{P}\left(\gamma \geq \gamma_{\mathrm{d}} \mid \mathrm{EQK}\right.} \int_{\frac{G}{G_{\max }}} \mathrm{P}\left(\gamma \geq \gamma_{t} \mid \mathrm{a}_{\max }, \mathrm{r}_{\mathrm{d}}, \frac{\mathrm{G}}{\mathrm{G}_{\max }}\right) f\left(\mathrm{a}_{\max } \mid \mathrm{M}, \mathrm{R}\right) f_{\mathrm{r}_{\mathrm{d}}}\left(\mathrm{r}_{\mathrm{d}}\right) f_{\frac{G}{G_{\max }}}\left(\frac{\mathrm{G}}{\mathrm{G}_{\max }}\right) \mathrm{d} \frac{G}{G_{\max }} \cdot \mathrm{dr}_{\mathrm{d}} \cdot \mathrm{da}_{\max }
$$

Combining results from the stress- and strain-based frameworks... 
Can magnitude-bound correlations be developed without field observations? YES!

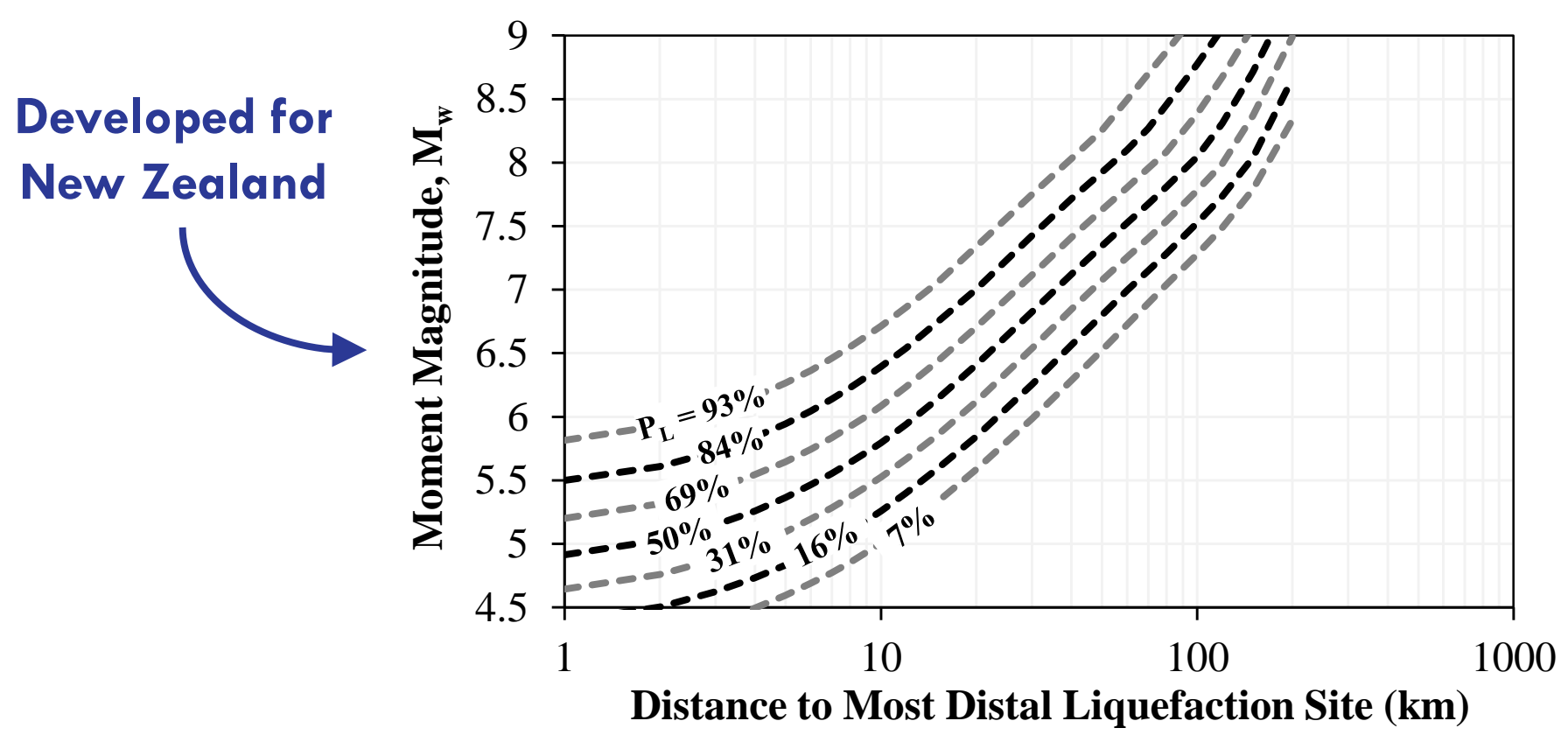


Can magnitude-bound correlations be developed without field observations? YES!

Developed for New Zealand
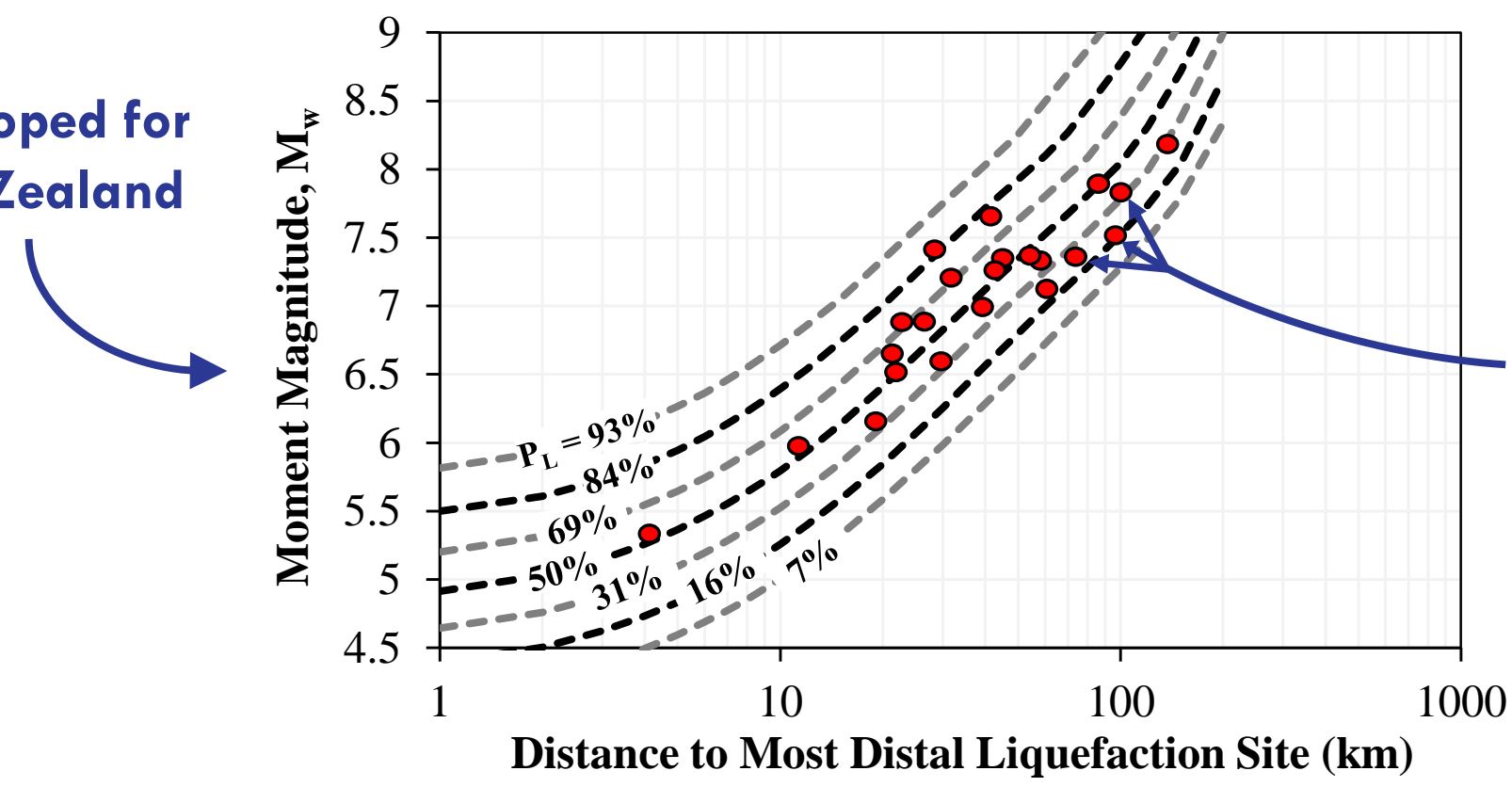

Empirical data from New Zealand...fits $\pm 1 \sigma$ mechanicsbased prediction

Distance to Most Distal Liquefaction Site (km) 

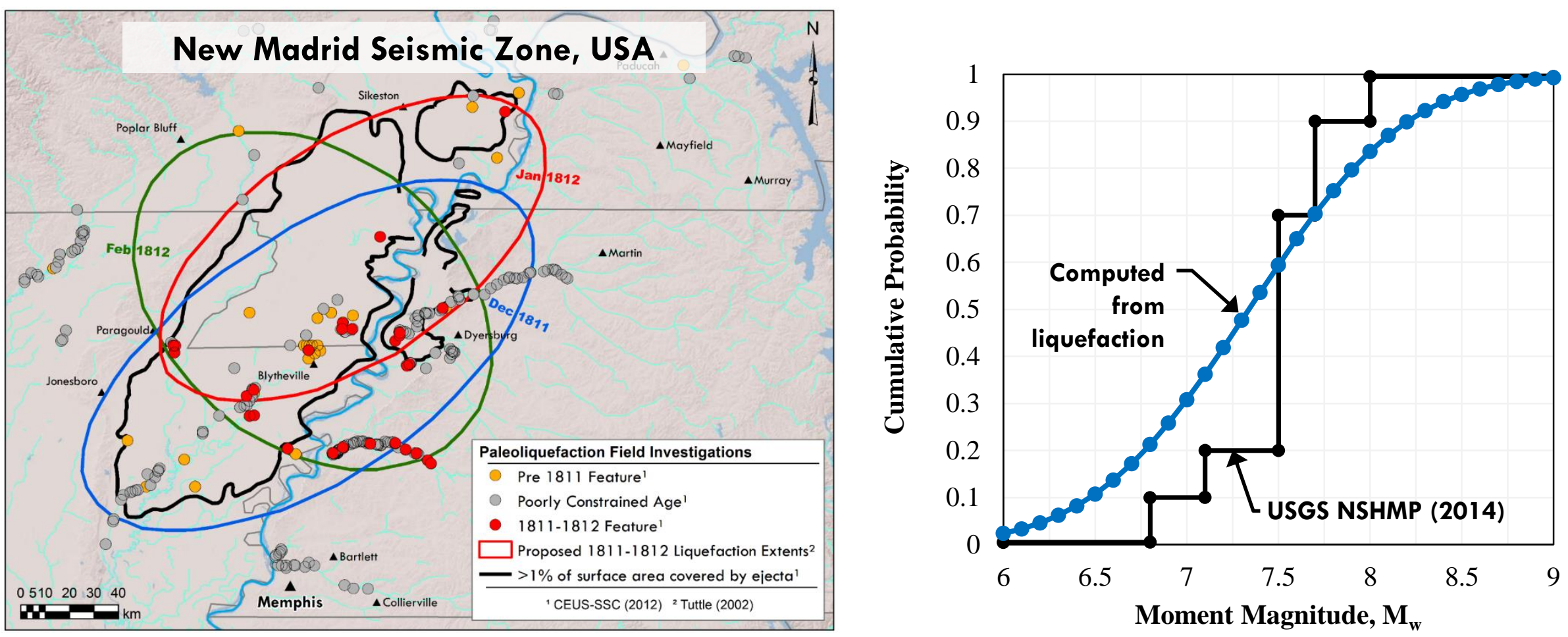

Much more informative, but still two problems:

1) Not all field evidence is utilized (from mechanics standpoint)

2) Must know/assume source location... what if we don't know? 
Combining all field data, we can compute the likelihood that an earthquake at a given location, having given magnitude, would produce a series of field observations:

$$
L(M \mid x)=P(X=x \mid M)=\prod_{i=1}^{N} P\left(X_{i}=x_{i} \mid M\right)
$$

EQ Source Location 1

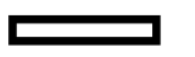

Source Location 1

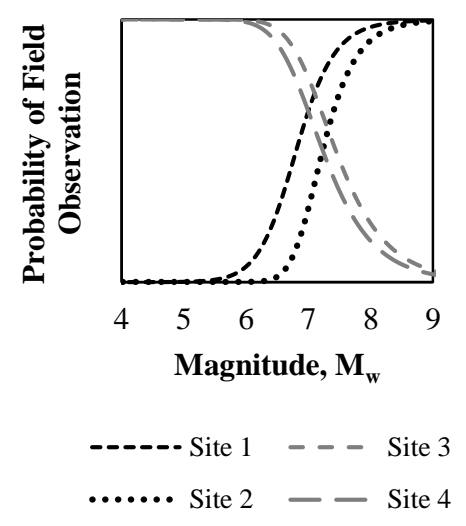

Source Location 2

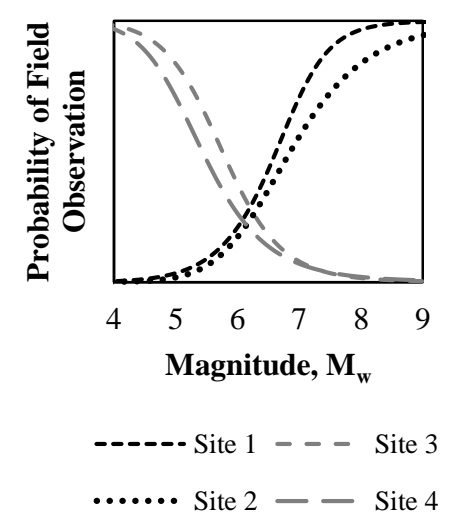

$\stackrel{1}{0} \quad \bigcirc_{3}^{\circ} \quad \stackrel{4}{\bigcirc}$

EQ Source Location 2

Likelihood of source locations and corresponding $\mathrm{M}$ distributions

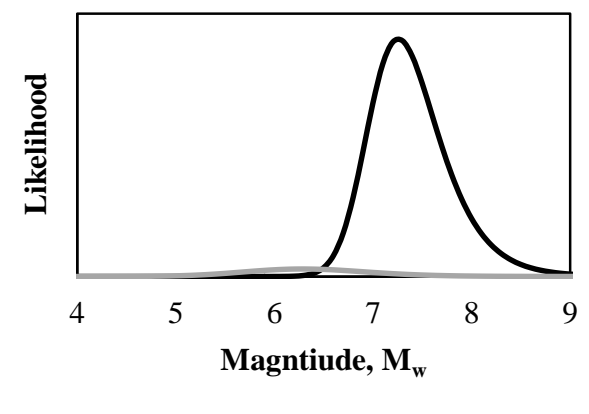

- Source Location 1 


\section{OUTLINE}

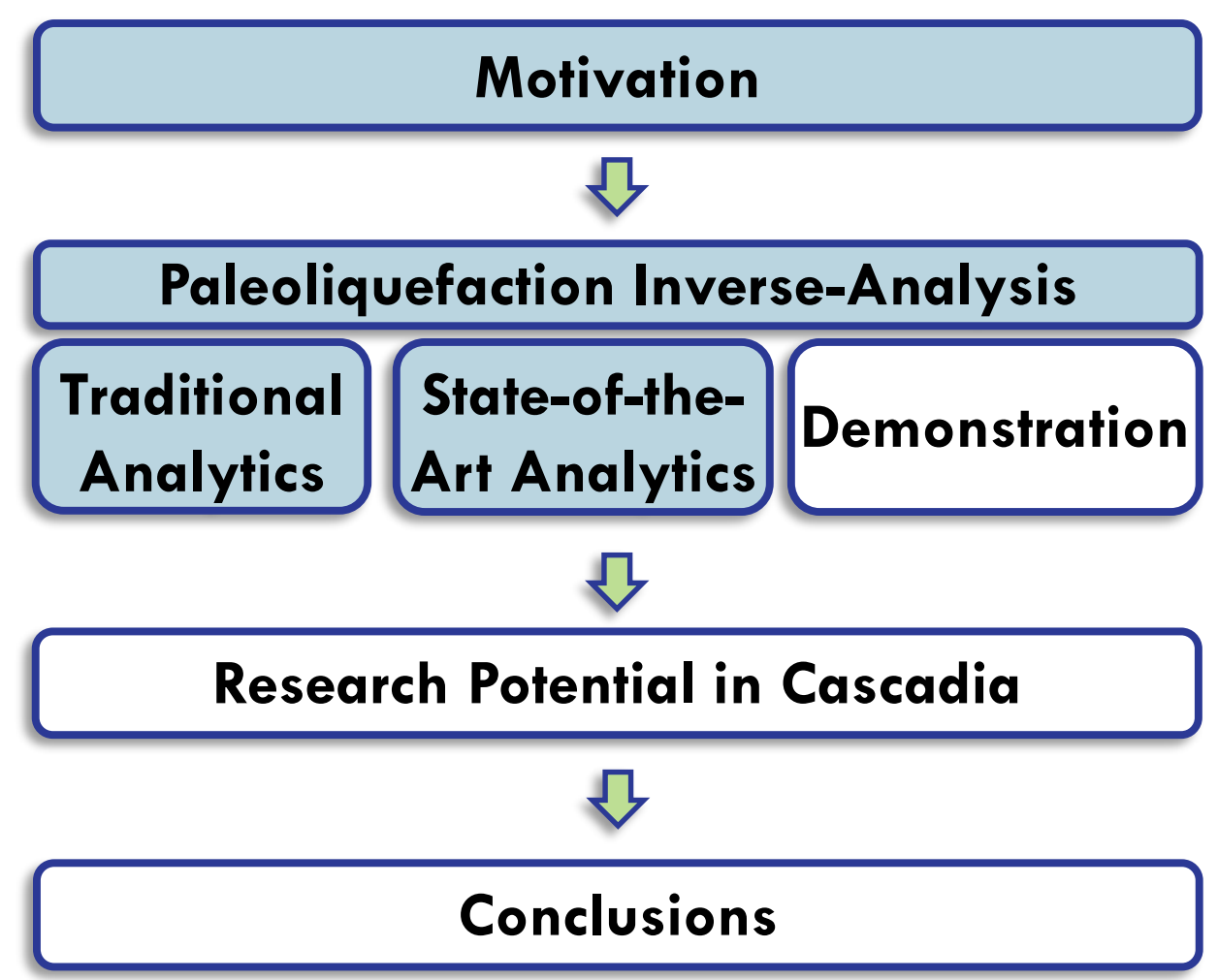




\section{OUTLINE}

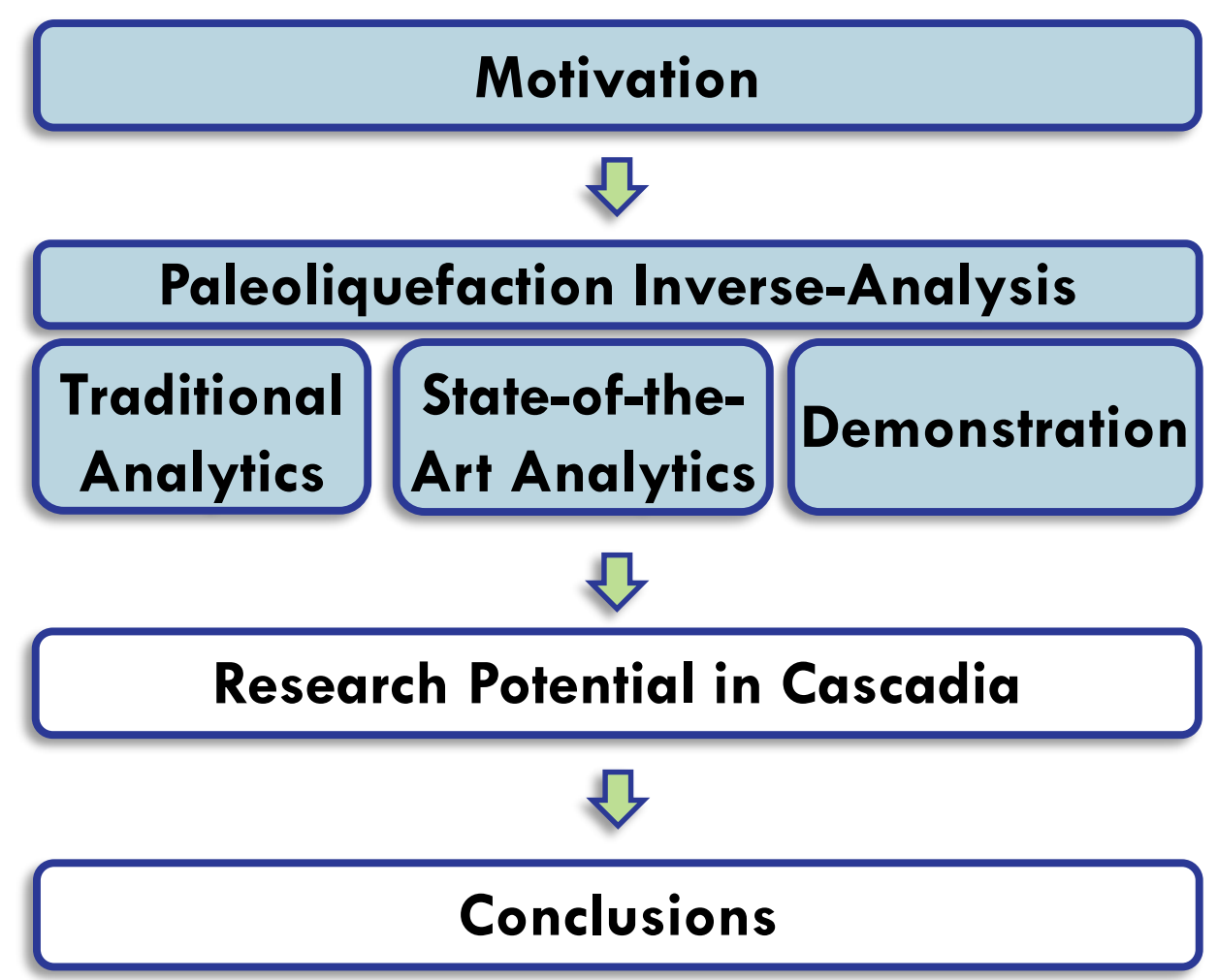




\section{Proof-of-Concept: 2011 Christchurch, New Zealand, Earthquake}

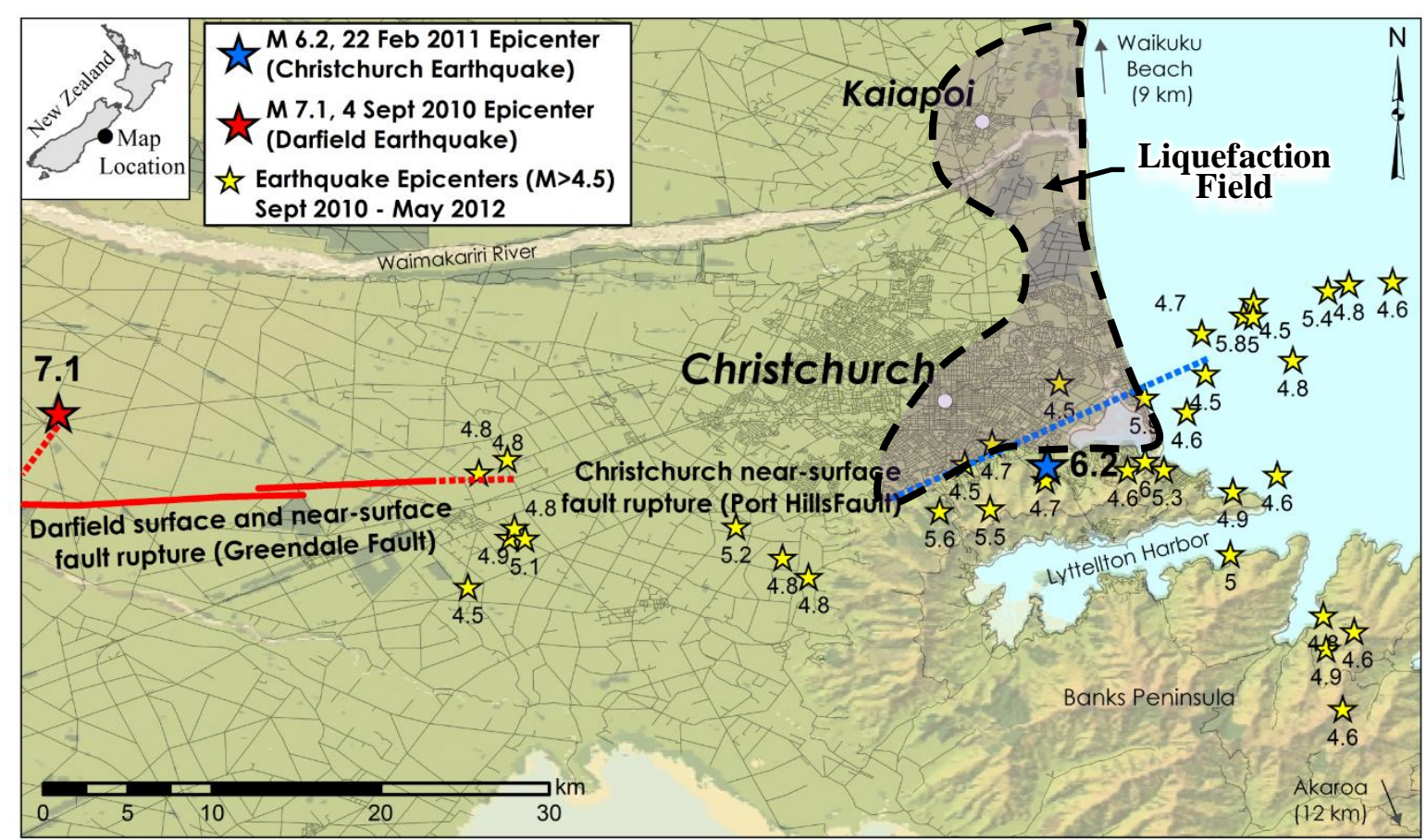


Proof-of-Concept: 2011 Christchurch, New Zealand, Earthquake

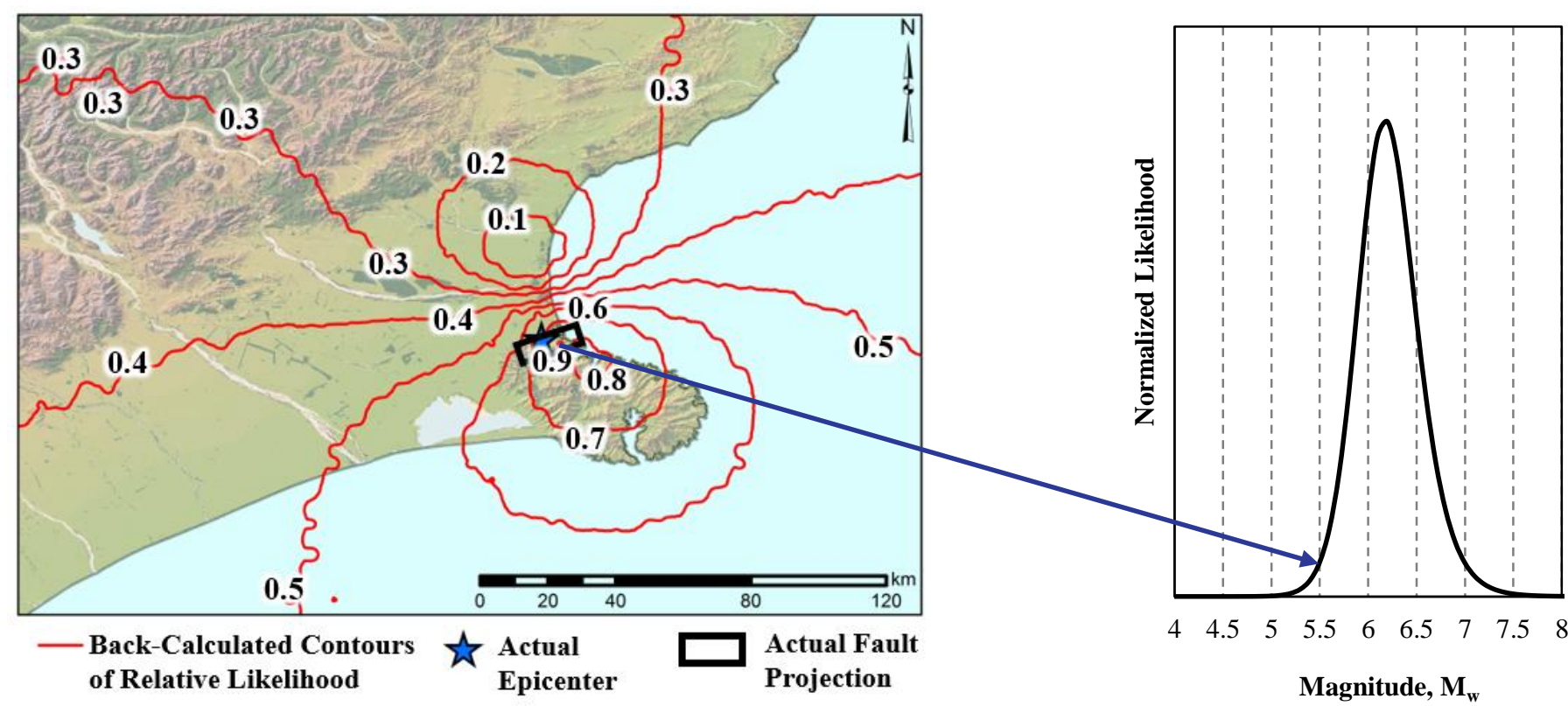

Findings:

1) Most likely source-location is within actual fault projection

2) Corresponding median magnitude (M6.25) is very close to actual (M6.2) 


\section{OUTLINE}

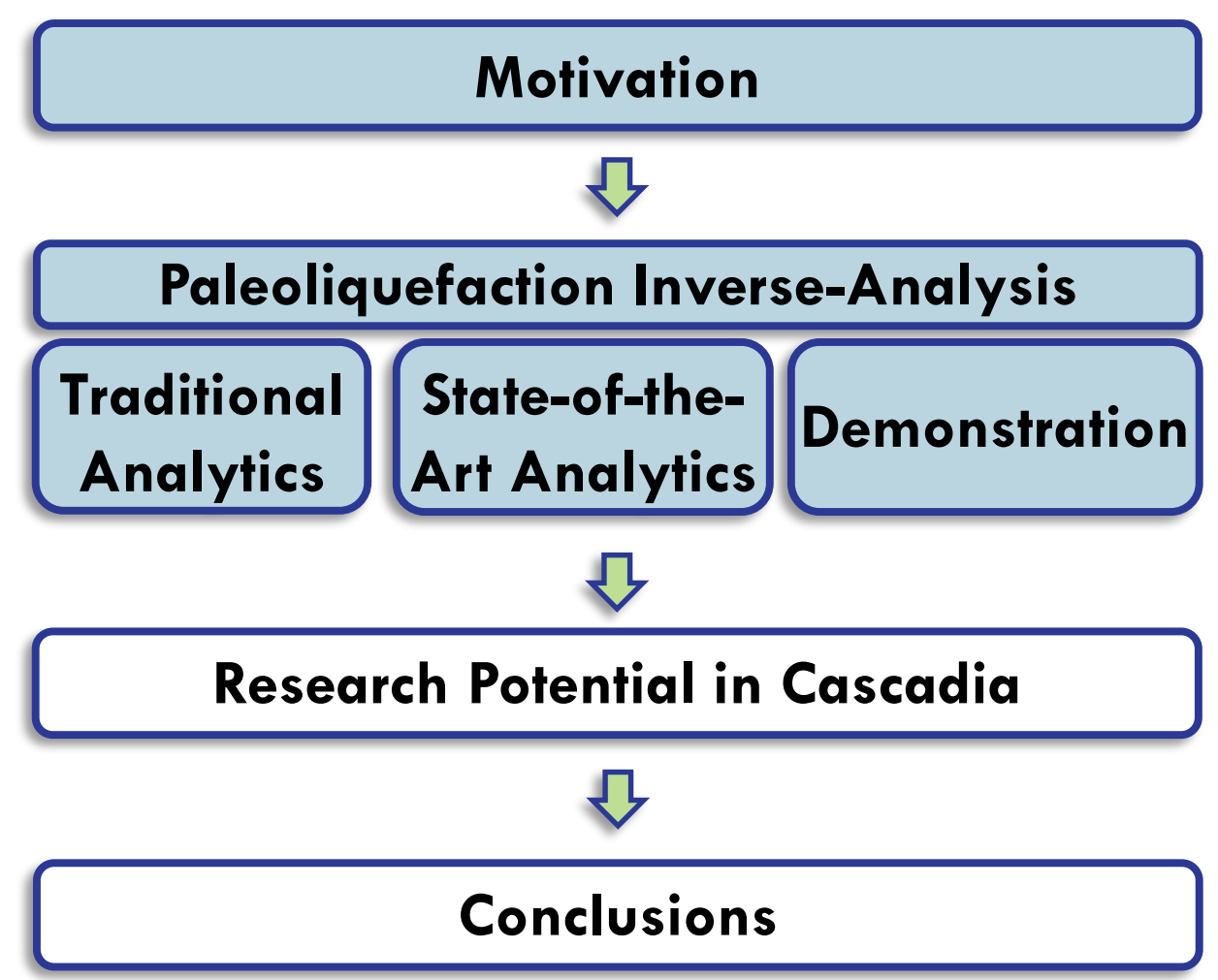




\section{OUTLINE}

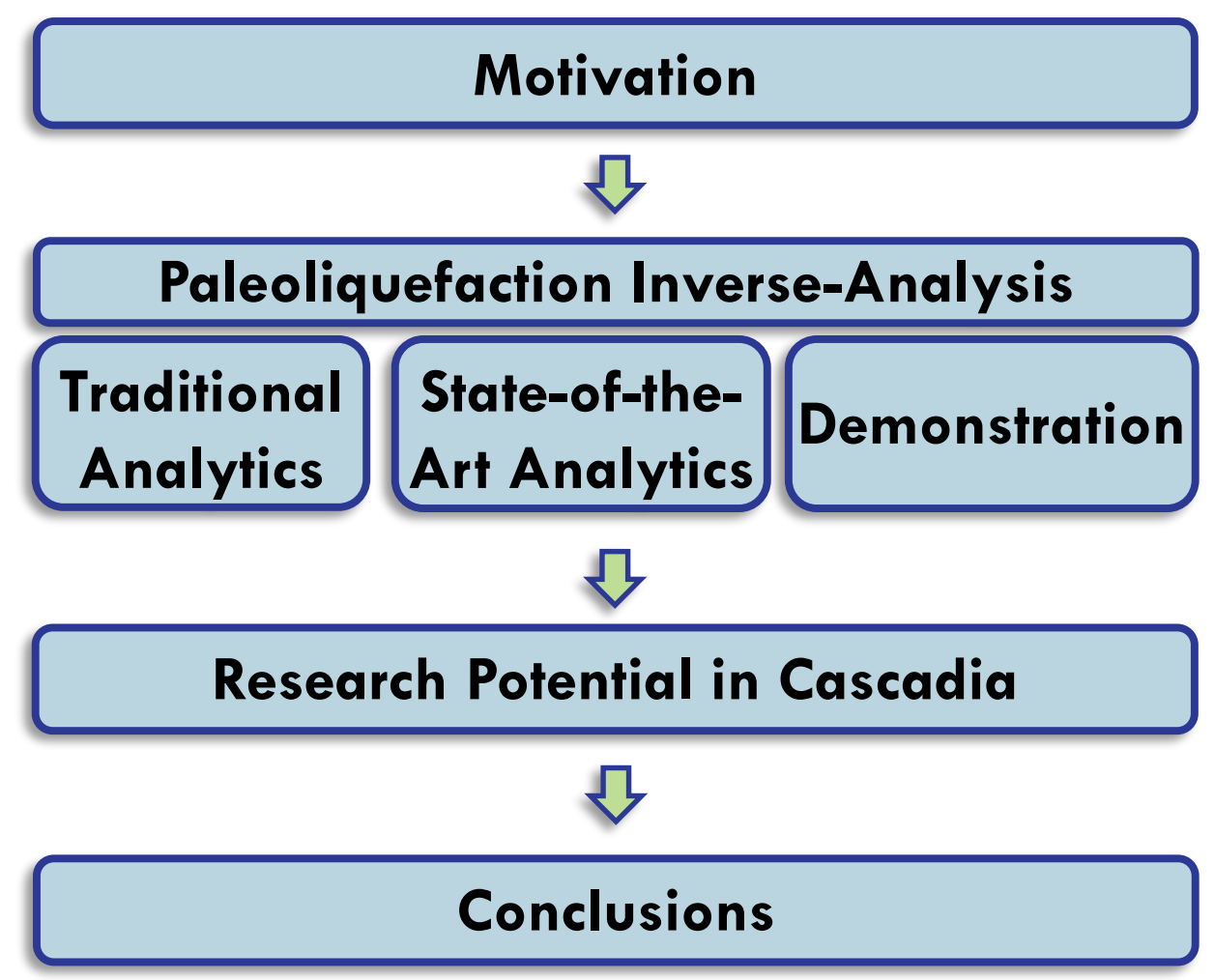


A public database compiling all paleoliquefaction data, to include

a. Location

b. Dating

c. In-situ geotechnical test data (very few known study-sites have this) $=\$$

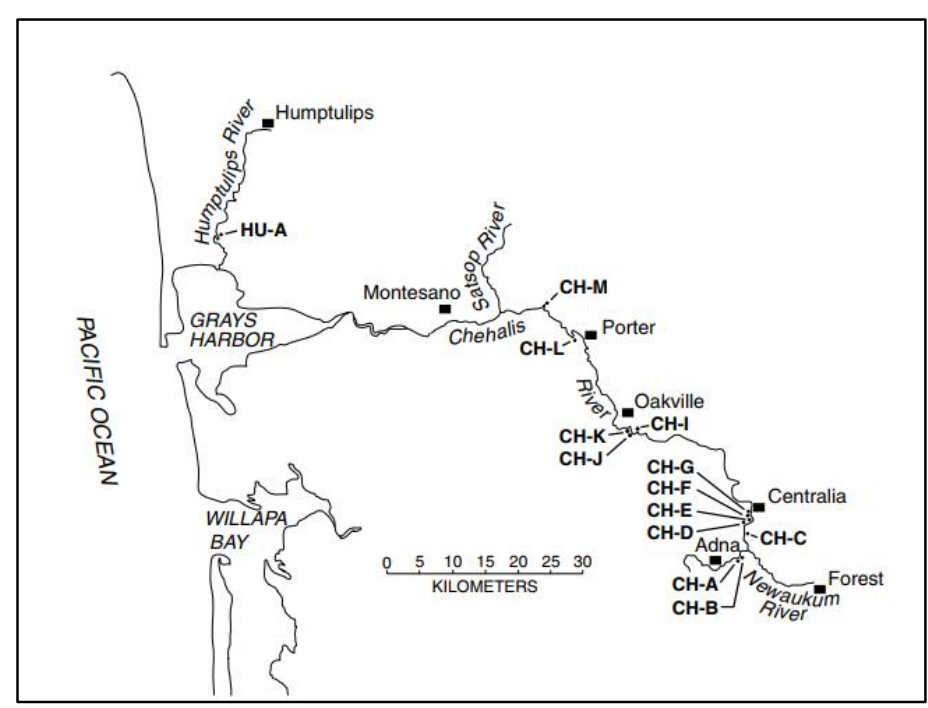

Obermeier and Dickenson (2000)

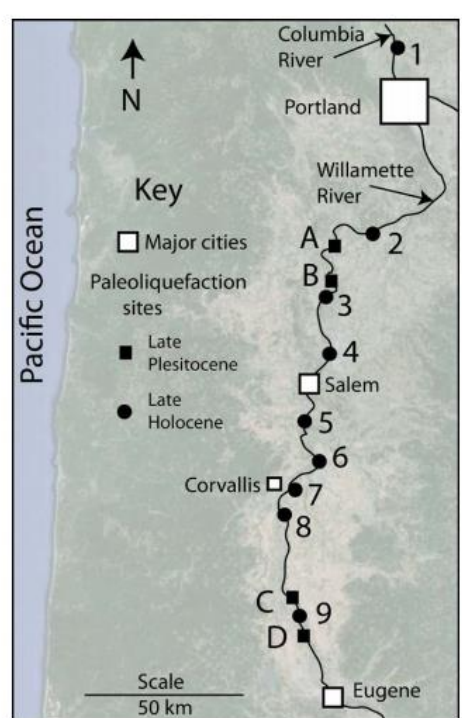

Peterson et al. (2014) 
Where does paleoliquefaction fit in the Cascadia puzzle?

\begin{tabular}{|c|l|l|l|l|l|}
\hline \multirow{2}{*}{ Type of Evidence } & \multicolumn{5}{|c|}{ Earthquake Characteristics Obtainable From Evidence } \\
\cline { 2 - 6 } & $\begin{array}{c}\text { Recurrence } \\
\text { Rate }\end{array}$ & Ground Motions & Rupture Location & Magnitude & Other Source Traits \\
\hline Dendrochronology & & & & & \\
\hline Diatoms/Microfossils & & & & & \\
\hline Other Subsidence Markers & & & & & \\
\hline Tsunami Deposits/Impacts & & & & & \\
\hline Turbidite Record & & & & & \\
\hline On-Fault Evidence & & & & & \\
\hline Landslides & & & & & \\
\hline Liquefaction & Limited & Very Strong & Strong & Strong & \\
\hline
\end{tabular}


$>$ Multidisciplinary collaboration is needed to exploit the results of field studies. $>$ Decades of work have too often ended in the use of very simple and debunked methods. This impacts our national seismic hazard maps.

$>$ New paleoliquefaction analytics can probabilistically compute:

$>$ Causative ground motions at individual sites.

$>$ Source location and magnitude distribution from regional evidence.

What is keeping up from applying these new analytics in the CSZ?

$>$ Existing data must be compiled from all researchers.

$>$ For most study-sites, in-situ geotechnical tests need to be performed. 
Bastin, S., Bassett, K., Quigley, M.C., Maurer, B.W., Green, R.A., Bradley, B.A., and Jacobson, D. (2016). "Late Holocene liquefaction at sites of contemporary liquefaction during the 20102011 Canterbury Earthquake Sequence." Bulletin of the Seismological Society of America 106(3): 881-903, Seismological Society of America.

Maurer, B.W., Green, R.A., Quigley, M.C., and Bastin, S. (2015). "Development of magnitudebound relations for paleoliquefaction analyses: New Zealand case study." Engineering Geology 197: 253-266, Elsevier Publishing.

Green, R.A., Maurer, B.W., Bradley, B.A., Wotherspoon, L., and Cubrinovski, M. (2014). "Implications from liquefaction observations in New Zealand for interpreting paleoliquefaction data in the central eastern United States." U.S. Geological Society Technical Report G12AP20002, 97pp. 